\title{
LA HERMENÉUTICA JURÍDICA DESDE LA PERSPECTIVA FILOSÓFICA
}

\section{LEGAL HERMENEUTICS FROM A PHILOSOPHICAL PERSPECTIVE}

\author{
MANUEL LÁZARO PULIDO \\ Universidad Nacional de Educación a Distancia \\ Universidad Bernardo O'Higgins
}

Recibido: 09/03/2019 Aceptado: 18/09/2019

\section{RESUMEN}

En este artículo partimos de la hermenéutica no tanto como método filosófico determinado, como la herramienta inherente a todo acto humano, especialmente en el de la toma de decisión. El derecho supone una toma de decisión tanto en el ejercicio legislativo como en la práctica judicial. Pero la interpretación humana siempre genera un estado de incertidumbre, al dar la impresión de que se trata de un acto privado de objetividad, más propio de la ciencia, lo que ha llevado a buscar un paradigma en derecho que sea científico y que se ha identificado muchas veces con el positivismo (empirismo) lógico. La perspectiva filosófica que proponemos es la del análisis de la propia naturaleza inherente del acto interpretativo, toda vez que ni el dato, ni el sujeto, ni la ciencia se pueden reducir a meros datos y hechos, sin tener en cuenta no solo el contexto de justificación, sino el de descubrimiento y la perspectiva sociológica. A ello sumamos las nuevas perspectivas de la neurociencia y la psicología cognitiva basada en la inferencia bayesiana que muestra, a su vez, cómo la percepción sensorial es leída por el cerebro desde un contexto cultural e histórico propio capaz de realizar un 
pensamiento proyectivo. Esto supone que el razonamiento analítico y la lógica deductiva y empírica no son suficientes a la hora de analizar unos datos que nunca son leídos de forma neutra (en bruto). En conclusión, la mejor forma de evitar la incertidumbre no consiste en cerrar los ojos a la evidencia de la interpretación, sino afrontarla con herramientas como la hermenéutica.

Palabras clave: Hermenéutica, Derecho, dato, acción, interpretación, inferencia bayesiana.

\section{ABSTRACT}

In this article we start from hermeneutics, not so much as a specific philosophical method, but as the inherent tool of every human act, especially in decision-making. Law implies decision-making both in the legislative exercise and in judicial practice. But human interpretation always generates a state of uncertainty, by giving the impression that it is a private act of objectivity, more typical of science, which has led to the search for a paradigm in law that is scientific and has often been identified with logical positivism (empiricism). The philosophical perspective that we propose is that of the analysis of the very inherent nature of the interpretative act, since neither data, nor the subject, nor science can be reduced to mere data and facts, without taking into account not only the context of justification, but also that of discovery and the sociological perspective. To this we add the new perspectives of neuroscience and cognitive psychology based on Bayesian inference that shows, in turn, how sensory perception is read by the brain from a cultural and historical context of its own that is capable of projective thinking. This implies that analytical reasoning and deductive and empirical logic are not sufficient when analyzing data that are never read in a neutral (raw) way. In conclusion, the best way to avoid uncertainty is not to close our eyes to the evidence of interpretation, but to face it with tools such as hermeneutics.

Keywords: Hermeneutics, Law, done, agency, interpretation, Bayesian inference.

Sumario: 1. Introducción. 2. Dos modelos de metodología legal: empirismológico y hermenéutica: 2.1. El positivismo jurídico y la pretendida neutralidad del hecho y del observador; 2.2. La legitimidad de la lectura interpretativa de 
los hechos. 3. Más allá del dato percibido. Razonamiento cognitivo y hermenéutica. 4. Conclusión.

\section{INTRODUCCIÓN}

Cuando hablamos de hermenéutica jurídica nos encontramos un marco general que responde a la propia ciencia o disciplina de la hermenéutica, y a su diferencia específica, el hecho de aplicarse y/o formar parte de la ciencia jurídica o de los actos jurídicos. De esta forma, la hermenéutica jurídica hace referencia a la interpretación del objeto central del acto jurídico: la ley, tanto en su formación y elaboración como en su actuación. La hermenéutica se presenta como uno de los elementos centrales de la epistemología jurídica, de una aproximación al conocimiento más cercano a la verdad, incluso una aproximación al conocimiento "científico" (episteme) de las condiciones de la verdad jurídica, y eso interesa a la filosofía jurídica en cuanto reflexión epistemológica sobre la ciencia del derecho ${ }^{1}$. La hermenéutica implica, pues, una reflexión no solo sobre la cuestión gnoseológica -qué tenemos que conocer-, sino sobre la constitución propia del conocimiento, es decir sobre la cuestión metodológica. La pregunta sobre el objeto y el método del conocimiento afecta, a su vez, a la propia axiología epistemológica: a la validez del conocimiento adquirido o producido ${ }^{2}$. Pensar la hermenéutica jurídica supone, pues, reflexionar, desde el punto de vista del conocimiento, sobre el estatuto epistemológico de la ciencia de derecho. Pero la hermenéutica jurídica no solo implica una reflexión epistemológica sobre la ciencia jurídica, sino que posee una vertiente práctica, ya que cumple una función pragmática, toda vez que aparece de forma espontánea en la práctica

\footnotetext{
1 “Contrairement à la dogmatique juridique, à la philosophie ou à la théorie du droit, l'objet de l'épistémologie juridique n'est pas "le droit" (quelle que soit la définition que l'on retienne de ce concept). Son objet est la connaissance sur le droit, ou, dans une acception plus stricte, la science du droit". Albane Geslin, "L'importance de l'épistémologie pour la recherche en droit", en La recherche juridique vue par ses propres acteurs [en línea], dir. Bertrand Sergues (Toulouse: Presses de l'Université Toulouse, 2016 (consultado el 15 de diciembre de 2018), http://books.openedition.org/putc/956, doi: $10.4000 /$ books.putc. 956 .

2 Jean-Louis Le Moigne, Les épistémologies constructivistes (Paris: PUF, 2007), 6.
} 
diaria llevada a cabo por los juristas, tanto por quienes la ejercen en su oficio como por quienes la estudian. En este sentido, entendemos "derecho", siguiendo a Jerzy Wroblewski, como "el conjunto de prescripciones que satisfacen las condiciones especificadas por una teoría jurídica particular, en este caso refiriéndose a los sistemas de derecho escrito" 3. Atendiendo tanto a las leyes y prescripciones promulgadas por el legislador como a las consecuencias que implican dichas formulaciones. Esta distinción nos ayuda a entender "la distinción entre el lenguaje jurídico como producción de actos normativos y el lenguaje de la aplicación de la ley"4.

En este sentido, la filosofía proporciona -o mejor, ha proporcionado - una oportunidad, a la vinculación entre ser y decir, señalando la escisión arbitraria entre dos ámbitos que siempre se dan trabados y que la hermenéutica trata de refutar rescatando la vinculación entre lo ontológico y lo epistemológico, esto supone que:

"lo que se dice remite a una realidad y que toda realidad, a la vez, sólo puede ser determinada, comprendida cuando es dicha, sin que la realidad pueda ser sustituida por una de las formas de decirla (como hace, por ejemplo, el positivismo normativo al equiparar el ser del derecho a la norma, que no es sino uno de los modos de decirlo) y sin que, a la inversa, las formas de hablar sobre la realidad puedan ser sustituidas por una supuesta realidad separada de todo lenguaje (como pretenden las corrientes emotivistas o no cognoscitivistas del derecho al afirmar que no cabe un conocimiento de este con arreglo a ningún sentido y, por tanto, que no puede ser dicho de ninguna manera, sino reducido a una suerte de sentimiento interno de justicia)" 5 .

La hermenéutica jurídica estudia, así, la interpretación y el significado del derecho escrito. Entender de una u otra forma la hermenéutica

3 Jerzy Wroblewski, “Les langages juridiques : une typologie”, Droit et société 8 (1988): 13.

4 Wroblewski, "Les langages juridiques", 14.

5 José Luis Muñoz de Baena, José Carlos Muinelo (coords.), Filosofía del Derecho. Lecciones de hermenéutica jurídica (Madrid: UNED, Sindéresis, 2019), 177. 
implica formas de aproximación interpretativas, balanceadas hacia el sujeto o hacia el contexto del objeto interpretado. En todo caso haríamos mal en entender de forma homogénea la hermenéutica.

Un recordatorio somero por la hermenéutica filosófica en el siglo veinte nos lleva al polo subjetivo de la hermenéutica tanto en Heidegger, Ser y tiempo (Sein und Zeit) ${ }^{6}$, 1927, como en Hans-Georg Gadamer, Verdad y Método (Wahrheit und Methode), 19607. La concepción subjetivista tiende a enfatizar la parte del sujeto en la interpretación frente a su uso instrumental-metodológico que había sido subrayado por la teología $\left(\right.$ Schleiermacher $\left.{ }^{8}\right)$, que, a su vez, se proponía como una reacción ante la metodología del positivismo científico. Este marco general de lectura sobre la interpretación como método y el papel del sujeto en el mismo, también se ha reflejado en diversas tendencias de las que destaca el decisionismo, que subraya el carácter decisional de la interpretación, y que tiene como uno de sus representantes a Carl Schmitt 9 . No menos conocido es el normativismo -origen en parte de la reacción de $\mathrm{Schmitt}^{10}$-, para quien la norma aparece como el criterio último de interpretación del derecho de modo que su aplicación presupone un acto elícito de voluntad, como señalara la célebre obra de Hans Kelsen, Teoría pura del Derecho ${ }^{11}$.

Así, la hermenéutica tiene un importante caudal especulativo, analítico, y doctrinal, tanto en las ciencias humanas, como en las ciencias

6 Martin Heidegger, Sein und Zeit, ed. por Friedrich-Wilhelm von Herrmann (Frankfurt am Main: Vittorio Klostermann, 1977) [Heidegger-Gesamtausgabe, Bd. 2, Abt. 1, Veröffentlichte Schriften 1914$1970]$.

7 Hans-Georg Gadamer, Wahrheit und Methode. Grundzüge einer philosophischen Hermeneutik (Tübingen: J.C.B. Mohr, 1975).

8 La colección Hermeneutik und Kritik aparece originalmente en Friedrich Daniel Ernst Schleiermacher, Sämtliche Werke (Berlín: Reiner, 1835-1864). Reedición en Hermeneutik und Kritik (Frankfurt a. M.: Suhrkamp, 1977).

9 Carl Schmitt, Politische Theologie Vier Kapitel zur Lehre von der Souveränität (München und Leipzig: Duncker \& Humblot, 1922). Cf. Gabriel L. Negretto, “¿Qué es el decisionismo? Reflexiones en torno a la doctrina política de Carl Schmitt", Revista Mexicana de Ciencias Políticas y Sociales 40 (1995): 49-74; José Peña (coord.), Carl Schmitt y el decisionismo jurídico (Madrid: Fundación Universitaria San Pablo CEU, 2015).

10 Emmanuel Pasquier, De Genève à Nuremberg. Carl Schmitt, Hans Kelsen et le droit international (Paris: Editions Classiques Garnier, 2012), 55-95 ("Le « Kelsen » de Schmitt. Construction par Carl Schmitt de l'opposition entre décisionnisme et normativisme").

11 Hans Kelsen, Reine Rechtslehre. Einleitung in die rechtswissenschaftliche Problematik, ed. por Matthias Jestaedt, sobre la primera edición de 1934 (Tübingen: Mohr Siebeck, 2008). 
sociales y de forma especial en la filosofía. Pero lo que hace importante a la hermenéutica es su realidad práctica. Es decir, el campo jurídico nos lleva día a día a tomar decisiones hermenéuticas. Decisiones que abarcan tanto el ámbito legislativo como el judicial afectando a todos sus protagonistas: justiciables, letrados, magistrados, jurados... Y esta actividad está tan enraizada e interiorizada que se ha vuelto mecánica. Ahora bien, este mecanicismo implícito, cuasi natural, inflaccionado no pocas veces por el positivismo y el mecanicismo del poder (Hart ${ }^{12}$ ), no reduce la dificultad del proceso interpretativo donde intervienen factores relacionales y diacrónicos. Hugues Rabault, analizando la dificultad de la interpretación de la ley, ha señalado los límites de dicho proceso. Por una parte, la cotidianeidad de la interpretación no anula el papel del sujeto. Por otra parte, la incertidumbre del proceso interpretativo invita, especialmente en derecho, a minimizarlo en la medida de lo posible, por ejemplo, mediante la aplicación lo más rigurosa posible de las escalas legales, por ejemplo, en derecho penal. A veces, señala Rabault, la interpretación es nula, es el caso de ciertas sentencias dentro del derecho administrativo:

"Así pues, puede decirse que, en general, la aplicación de las normas jurídicas no está sujeta a ninguna incertidumbre, ya que los intérpretes están sujetos a una red de limitaciones técnicas y jerárquicas (jerarquía de jurisdicciones, por ejemplo). Se trata de una experiencia comúnmente referida por los jueces, la de situaciones en las que el intérprete formula una solución técnicamente inevitable, a pesar de su sentimiento subjetivo de ir en contra de la equidad (situaciones resumidas por el adagio, summum jus, summa injuria [el más alto derecho, la mayor injusticia])"13.

12 Herbert L.A. Hart, The Concept of Law, ed de Postscrip por Penelope A. Bulloch y Joseph Raz, intr. y not. por Leslie Green, $3^{\mathrm{a}}$ ed (Oxford: Oxford University Press, 2012). Un estudio al respecto en Massimo La Torre, "Le modèle hiérarchique et le Concept de droit de Hart", Revus 21 (2013): 117-139. 13 Traducción mía: "On peut ainsi dire que, généralement, l'application des normes juridiques ne comporte aucun aléa, les interprètes étant enserrés dans un réseau de contraintes techniques et hiérarchiques (hiérarchie des juridictions, par exemple). C'est une expérience couramment évoquée par les juges que celle de situations où l'interprète formule une solution techniquement inévitable, malgré le sentiment subjectif qui est le sien d'aller à l'encontre de l'équité (situations résumées par l'adage, summum jus, summa injuria [le plus haut droit, la plus grande injustice])". Hugues Rabault, "Le problème 
Pero, el peligro intrínseco e inherente a la interpretación no implica que se pueda anular en todos los casos, incluso sería discutible que se debiera anular en aquellos lugares interpretativos donde los hombres "de carne y hueso" se sienten concernidos (si la interpretación resulta un terreno resbaladizo por su componente humano -inseguro y personal-, el procedimentalismo mecanicista resulta un terreno resbaladizo en lo humano -seguro e impersonal-). Si bien la especificidad de la hermenéutica jurídica corresponde a su naturaleza pragmática y funcional; sin embargo, dicha especificidad no puede anular su punto común, es decir, la necesidad de mantener el equilibrio entre los polos epistemológicos y ontológicos.

Es cierto que el derecho moderno se concibe como un sistema técnico de procedimientos que rigen los detalles de la vida social. En este sentido, en su desarrollo cotidiano nacido del imaginario de la novedad de la modernidad, está muy lejos la ambición original de constituir una regla de justicia (tradición iusnaturalista de Tomás de Aquino ${ }^{14}$ ), al menos si la consideramos esta como un espacio totalmente especulativo. Efectivamente, la hermenéutica legal toma distancia -sin olvidar- de la teoría de la interpretación aristotélica aparecida en Peri hemeneias ${ }^{15}$ desarrollándose a partir de la interpretación de la filosofía grecorromana y la recepción medieval del derecho romano. La filosofía medieval suma, por una parte, la custodia, interpretación y transmisión de los grandes textos del derecho romano que era una tradición jurídica de ius scriptum de códigos y codificaciones, con la especulación sobre la finalidad del derecho en la comunidad ${ }^{16}$. Se crea así el propósito fundante del derecho

de l'interprétation de la loi : la spécificité de l'herméneutique juridique”, Le Portique. Revue de philosophie et de sciences humaines 15 (2005) § 4. Consultado el 3 de marzo de 2019, URL: http://journals.openedition.org/leportique/587.

14 Michel Bastit, "La justice générale selon saint Thomas : une politique de la félicité", Revue thomiste 114 (2014): 129-142.

15 Cf. Jean Isaac, Le Peri hermeneias en occident de Boèce à Saint Thomas. Histoire littéraire d'un Traité d'Aristote (Prais: Vrin, 1953).

16 Peter Goodrich, "Legal hermeneutics", en Routledge Encyclopedia of Philosophy Online, ed. Edward Craig, Tim Crane (Londres, Nueva York: Routledge 1998), consultado el 25 de febrero de 2019, doi: 10.4324/9780415249126-To16-1. 
occidental que nace de la aplicación intelectual y conceptual del pensamiento sobre la ley en general del pensamiento griego a partir del pragmatismo y del sentido de aplicabilidad del derecho romano. Y ello no merma en absoluto el universo meramente conceptual-especulativo, sino que viene referenciado -en Tomás de Aquino y en la posterior escolástica- a una teorización que tiene como fin resolver los problemas que causan litigio en su época. De esta forma, se da lugar en el medievo -origen genuino del pensamiento occidental moderno- a una disciplina ejemplar de la hermenéutica. Hermenéutica que tiene como fin la conservación, comparación, traducción y aplicación de los textos disponibles de la tradición jurídica a su contexto dado, estableciéndose como una auténtica disciplina textual especulativa y con vocación práctica, sin reducirse a ser una disciplina relacionada con la retórica forense, el estudio de la argumentación oral y la persuasión en los tribunales.

La reflexión teológica del derecho operada en el medievo y reflejada en el pensamiento de Tomás de Aquino, pero no solo en él, en una especie de teología del derecho, está en consonancia, con el derecho de su tiempo. Seguirá, pues, el modelo clásico del derecho romano en el que, sin rupturas con el pasado, y en el más acendrado respeto a la tradición, los jurisconsultos estaban convencidos de que el Derecho, como decía Cicerón, se forma por el devenir de los siglos y se consolida por el uso y la antigüedad (saeculis et aetatibus, usu ac vetustate ${ }^{17}$ ). No obstante, este convencimiento rechaza todo inmovilismo y se adaptan a los nuevos tiempos y circunstancias. Este acervo romano, recuperado por el descubrimiento del Digesto o Pandectas en Bolonia en el siglo XII supone un impulso especulativo que supera los particularismos locales y la anarquía legislativa desde un principio hermenéutico adaptativo de modo que se une tradición legislativa e interpretativa a necesidades particulares, como se ve en las codificaciones como el Código de las Siete Partidas de Alfonso X

17 Marco Tulio Cicerón, De Re Publica, 2, 1-2 (Cambridge: Harvard University Press, 1961), 111-112. 
el Sabio (1263-1265), que inspirado en el Corpus Iuris y en los glosadores y canonistas, armoniza con el Derecho castellano ${ }^{18}$.

Podríamos decir que la tradición hermenéutico-interpretativa depende de diversos topos antropológicos, lógicos y metafísicos -objetivosubjetivo; contextual-metodológico; epistemológico-ontológico-, en los que subyace su función de aplicación. Dependerá también de los diversos lenguajes del discurso según se formulen o se hable de las leyes que afectarán a la semántica y la pragmática del lenguaje, sea un lenguaje jurídico jurisprudencial, relativo a las decisiones en el campo aplicativo de la ley, sea el lenguaje jurídico científico como específico del discurso de la ciencia jurídica, sea el lenguaje jurídico común. Lenguajes que expresan las diferentes posiciones hermenéuticas, pues no es lo mismo buscar la justicia como regla y medida de la aplicación jurídica, que realizar una interpretación nacida de un sujeto carismático o de una decisión apoyada en la tecnificación anónima y fría.

La hermenéutica está ahí, porque la interpretación aparece inevitable en muchas ocasiones con relación a la vida, y con relación a la ley (no solo desde la acción del acto jurídico sino también en su función legislativa). En este sentido existe una correlación que ha de ser pensada entre lo correcto (el carácter procedimental como método epistemológico) y lo bueno (el carácter ontológico). En este sentido, cabe recordar la tercera acepción del Diccionario de la Lengua Española en la que define la ley en su significado jurídico como: "Precepto dictado por la autoridad competente, en que se manda o prohíbe algo en consonancia con la justicia y para el bien de los gobernados". Más allá de otras consideraciones podemos destacar que se afirma que su contenido debe estar "en consonancia con la justicia y para el bien de los gobernados”, de modo que ni siquiera el aspecto procedimental escapa al ámbito ontológico

18 Manuel J. Garrido, “Capítulo 1. Los orígenes y la Historia del Derecho", en Manuel J. Garrido et al., Nociones Jurídicas Básicas. Versión actualizada (Madrid: Editorial Universitas, 2012), 29. 
fundamental en su carácter de búsqueda de la justicia y la bondad, o mejor, la corrección está subsumida a dicho fin.

Es cierto que para evitar la posibilidad que podría dar lugar a una interpretación de la arbitrariedad en un contexto de lo correcto frente a la bueno, el sistema legal de las sociedades desarrolladas implica la producción mecánica y diaria de miles de soluciones jurisdiccionales, administrativas y de otro tipo, con el fin de reducir al mínimo la posibilidad de la arbitrariedad que pueda nacer del sujeto. Pero el sistema de contrapeso a la arbitrariedad que pueda nacer del acto interpretativo no se anula solo con actos y procedimientos externos, toda vez que cualquier acto sobre un hecho jurídico mantiene de forma intrínseca al propio acto una interpretación, la resolución por parte de un sujeto (o sujetos) en forma decisional de un problema que ha de ser resuelto, porque eso es inherente al acto jurídico, tanto a la hora de legislar como a la hora de juzgar. No cabe una consideración meramente procedimental o una reflexión ajustada al dato puro como si este pudiera escapar a la interpretación, se hace necesario afrontar dicha lectura interpretativa de la ley realizada por los actores del derecho con el fin de, desde ahí, acotar las limitaciones. Se hace, pues, necesario recabar en la especificidad de la hermenéutica jurídica como ámbito de decisión inevitable, más allá de la consideración de la objetividad irreal de todo hecho en sí, como ha considerado el positivismo lógico y su lectura jurídica.

\section{DOS MODELOS DE METODOLOGÍA LEGAL: EMPIRISMO-LÓGICO Y HERMENÉUTICA}

2.1. EL POSITIVISMO JURÍDICO Y LA PRETENDIDA NEUTRALIDAD DEL HECHO Y DEL OBSERVADOR

Arthur Kaufmann señala cómo es necesario superar los dualismos entre Derecho natural y positivismo jurídico y la separación entre ser y deber ser, resultante de un antagonismo abstracto que no se da en la 
realidad jurídica. Según el profesor alemán, hay que abandonar la tesis de que el derecho sea idéntico a las normas legales. Propone una comprensión del derecho desde el punto de vista hermenéutico. De esta forma, la hermenéutica jurídica es una herramienta útil a la hora de eliminar la ilusión de que la aplicación del derecho consiste en una subsunción exacta del caso en la ley. Kaufmann sitúa la hermenéutica como una solución a la dialéctica establecida entre dos tipos de racionalidades: el derecho natural y el positivismo jurídico, dos discursos de tenor lógico que olvidan la comprensión que precisa todo texto lingüístico (incluido la ley surgida en el derecho), y que supone, a su vez, una precomprensión, sin la cual el juez nunca podría poner en correspondencia la ley y el caso:

"No hay duda de que el apartamiento del iusnaturalismo y del positivismo jurídico y el acercamiento a la hermenéutica jurídica no significa facilitamiento alguno ni para el legislador ni para el juez. Por el contrario, se hace más difícil establecer o decir derecho, aunque también se hace más humano. El derecho natural racionalista y el positivismo jurídico habían convertido a los juristas, y más aún al juez, en funcionarios. La hermenéutica jurídica quiere devolverles personalidad"19.

En su reflexión Kaufmann opera una equiparación racionalista del iusnaturalismo y el positivismo jurídico que olvida tanto los matices del iusnaturalismo como del positivismo y los diferentes esquemas metafísicos y soluciones ontológicas y lógicas subyacentes al mismo. Reducción que se muestra más "sangrante" en las diferentes soluciones dadas por el primero (el iusnaturalismo). Efectivamente, no se puede hablar de una sola teoría iusnaturalista, pues esta proporcionará soluciones diversas y matices diferenciados en materia política y jurídica se atienda o no a una metafísica de lo sobrenatural o de lo natural y, a su vez, en lo sobrenatural se tenga en cuenta una metafísica de la existencia o de la esencia, cuyas derivaciones en filosofía del derecho se sustantivan en las potencialidades concernidas -entendimiento y la voluntad-, que afectan a la

19 Arthur Kaufmann, "Entre el iusnaturalismo y positivismo hacia la hermenéutica jurídica", Anales de la Cátedra Francisco Suárez 50 (2016): 142. 
propia comprensión de la entrada del contexto humano de decisión. No podemos entrar en estos importantes matices, pero es necesario indicarlo, porque, a nuestro juicio, la hermenéutica toma su amplitud metafísico-ontológica sobre la base del derecho natural concernido a los hombres, de modo que se presenta como el espacio de comprensión del sujeto humano pensado y recreado por la escuela iusnaturalista (especialmente útil en la versión de la voluntad común presente en la escuela franciscana). De este modo, puede la hermenéutica propuesta por Kaufmann escapar del subjetivismo judicial y del psicologismo o el sociologismo y puede sustanciar su pretensión de afirmar que no existe ninguna corrección del derecho fuera del proceso concreto que debe surgir a partir de la reflexión, la argumentación, el intersubjetivismo y el consenso de los participantes

De este modo, nos encontramos realmente con una corrección metodológica inherente a todas las ciencias -como vamos a intentar mostrar- y que se hace especialmente visible y un factor más decisivo en las ciencias o disciplinas humanas y sociales. En fin, nos preguntamos qué factores intervienen en la toma de decisiones relativos y en torno a la norma jurídica, más allá de la propia ontología subyacente, aunque las consecuencias afecten muchas veces de forma filosófica a dicha ontología. Se trata, pues, de la observación de dos modelos de la lectura del hecho en general (si la reflexión se extiende a todas las ciencias) y del hecho jurídico que alimenta la ley en particular (tanto en su formulación como en su aplicación), en nuestro caso. Dos modelos -el empírico-lógico y el hermenéutico-contrapuestos (Charles Taylor ${ }^{20}$ ) que se visualizan especialmente en las ciencias humanas y sociales, provocando una fuerte oposición entre los investigadores que se adhieren a uno u otro modelo. Las posiciones están, en principio, menos establecidas en derecho, al menos teóricamente, si bien no es así de forma práctica, como reflejan los planes de estudio de las propias facultades de derecho, donde no pocas

20 Charles Taylor, La liberté des modernes (Paris: PUF, 1987), c. 5 (L’interprétation et les sciences de l'homme). 
veces las materias teóricas (especialmente en el ámbito filosófico) son reducidas al mínimo sino miradas con cierto desdén.

La cuestión que descansa en el fondo de dicha diatriba versa sobre el estatuto objetivo del hecho como epicentro del criterio verificacionista de la metodología positivista. Charles Taylor considera que dicho modelo, presente en las ciencias naturales, no puede extenderse a las ciencias humanas y sociales, donde los hechos brutos no pueden confrontar las interpretaciones de validación, ya que la realidad social se construye mediante significaciones intersubjetivas, significaciones que están "enraizadas en las prácticas sociales [...] y que constituyen la matriz social en la que los individuos se sitúan y actúan" ${ }^{21}$. Nosotros pensamos, no solo lo que afirma Taylor sobre la pertinencia de la lógica del modelo verificacionista en ciencias sociales y humanas, sino que el propio dato bruto está impregnado de intersubjetividad e interpretación en todas las aproximaciones humanas, pues la ciencia no escapa como actividad humana al carácter humano y social (subjetivo e intersubjetivo). De este modo, lo que se evidencia es la imposibilidad de un "dato" epistemológicamente puro, y de un "hecho" dado puro, puesto que el "hecho" está mediado por la percepción espacio-temporal de un observador o de un conjunto de observadores que se vuelven científicos no solo al observar el "hecho" sino al introducir un lenguaje (humano) lógico-matemático que es, en sí, una interpretación del propio "hecho".

Este marco general -el modelo empírico-lógico- aplicado al derecho tiene como referencia básica el positivismo científico. Su influencia en la metodología del derecho se debe en parte al positivismo jurídico, cuyas relaciones con el positivismo científico resultan ser ambiguas.

El positivismo jurídico, en cuanto versión en el campo de las ciencias sociales del positivismo científico y basado en la posición filosófica del positivismo y empirismo lógico, toma como base el conocimiento basado en la observación objetiva de la realidad. Este modelo considera que el

21 Taylor, La liberté des modernes, 163. 
observador es neutral, pasivo, de modo que el objeto estudiado existe independientemente de él, de forma que la observación, si es válida, no difiere de la que hubieran hecho otros. La experimentación se presenta como el espacio de verificación de los datos. El observador "neutro" de los datos que se presentan de forma neutra utiliza un lenguaje lógicomatemático, actuando de una forma alejada de la subjetividad. El criterio usado para determinar la verdad de un enunciado es la verificación que opera por la demostración y por la experiencia. Mientras la demostración se refiere a los lenguajes formales (lógico-matemáticos) que se presentan en formas a priori; la experiencia se utiliza para aquellos enunciados $a$ posteriori (el caso de la ciencia y de los enunciados realistas), usando así un criterio extralingüístico para su verificación. Todos los enunciados con sentido pertenecen a una de las dos categorías (a priori-a posteriori) bajo el criterio de verificación correspondiente. El observador, si quiere serlo enunciando de forma informativa, debe prescindir de los elementos que no pueden reducirse a su contenido, de modo que evite todo juicio ético o estético. Para ello ha de prescindir de cualquier discurso moral o axiológico, centrándose en su función descriptiva. Se utiliza, así, un lenguaje único para toda ciencia (el derecho en cuanto ciencia también) construido con proposiciones verdaderas susceptibles de ser analizadas. En modelos apriorísticos y experimentales domina el hecho en bruto modelado por el uso de los lenguajes formales, se suma al empirismo experimental, el racionalismo lógico, que en los últimos tiempos ha encontrado en la aplicación informática una potente herramienta. Como señalan Michelle Cumyn y Mélanie Samson:

"La metodología del derecho se ha visto atraída por el modelo empíricológico en diversos niveles. El derecho, en primer lugar, ha recurrido de forma cada más frecuente a la pericia científica para probar los hechos en los que se basa la decisión jurídica. Las reglas del derecho, a su vez, se han presentado como datos en bruto (sin procesar), en el sentido definido por Taylor. El trabajo de los teóricos del derecho positivista ha sido fundamental en este sentido. La pirámide de las normas de Kelsen, la regla de 
reconocimiento de Hart, la teoría de las fuentes del derecho en la tradición civilista y la regla del precedente en la tradición inglesa tienen todas por objeto identificar las reglas del llamado derecho "positivo", lo que existe en un lugar dado y en un momento dado, utilizando criterios objetivos que dejan el menor espacio posible a la interpretación"22.

El positivismo jurídico extrae del positivismo filosófico y sociológico la idea de que la neutralidad del observador tiene como origen "que el objeto de la ciencia del derecho es un objeto desprovisto de transcendencia, un objeto positivo, perteneciente a un mundo sublunar" ${ }^{23}$. Desde ahí extrae la neutralidad axiológica del observador, del estudioso, del sabio. Esto conlleva, no pocas veces, el convencimiento, desde la tesis irrefutable de la neutralidad del dato, de que el rigor empírico en el tratamiento de los hechos y las fuentes del derecho, junto al rigor lógico (modelo empírico-lógico), reforzará la metodología jurídica dotando al derecho de un carácter científico. Pero como señalan Michelle Cumyn y Mélanie Samson "parece obvio que los juristas, especialmente los profesores de derecho, no practican el método que profesan”24.

Efectivamente la utilización exclusiva y reductiva de la metodología positivista en derecho crea conflictos irresolubles especialmente en la argumentación jurídica, especialmente en aquella que ha de enfrentarse al

22 Traducción mía: "La méthodologie du droit a subi l'attraction du modèle empirique logique à plusieurs niveaux. Le droit a d'abord eu recours de plus en plus souvent à l'expertise scientifique pour prouver les faits sur lesquels se base la décision juridique. Les règles de droit ont à leur tour été présentées comme des données brutes, au sens où les définit Taylor. Les travaux des théoriciens du droit positivistes ont été déterminants à cet égard. La pyramide des normes de Kelsen, la rule of recognition de Hart, la théorie des sources du droit dans la tradition civiliste et la règle du précédent dans la tradition anglaise ont toutes pour objet d'identifier les règles du droit dit " positif », celui qui existe dans un lieu donné et à un moment donné, à l'aide de critères objectifs qui laissent le moins de place possible à l'interprétation". Michelle Cumyn, Mélanie Samson, "La méthodologie juridique en quête d'identité", Revue interdisciplinaire d'études juridiques 71 (2013): 5. doi: https://doi.org/10 .3917/riej.071.0001

23 Traducción mía: "Avec le positivisme philosophique et sociologique, le positivisme juridique partage en effet l'idée que l'objet de la science du droit est un objet dénué de transcendance, un objet positif, appartenant au monde sublunaire". Alexandre Viala, "Le positivisme juridique : Kelsen et l'héritage kantien", Revue interdisciplinaire d'études juridiques 67 (2011): 95, doi: https://doi.org/10.3917/riej.067.0095

24 Traducción mía: "Pourtant, il nous apparait évident que les juristes, en particulier les professeurs de droit, ne pratiquent pas la méthode qu'ils professent". Cumyn, Samson, "La méthodologie juridique en quête d'identité", 6 . 
hecho de la modificación en la aplicación. La argumentación lógica puede aplicarse de forma más sencilla cuando se trata de ver la aplicación de la ley en un marco de racionalidad teórica (aplicación mecánica), pero en la puesta en práctica del mundo real en la que se precisa ajustar la norma a través de la argumentación realizada por el litigante o por el juez (interpretación creativa), la guía clara del razonamiento lógico se vuelve borrosa, como por otra parte también no pocas clarificaciones del "hecho" cegando así de forma literal una argumentación razonada. Es decir, se vuelve imprecisa en no pocas tomas de decisiones jurídicas. Tener en cuenta estos límites no supone restar racionalidad al derecho, sino dotar de armas interpretativas a los hechos que se presentan en la mayor parte de veces interpretables y que afectan al conjunto de la labor jurídica, pues los hechos alimentan las leyes en la acción legislativa y se presentan como realidades de aplicación de la ley en la acción judicial. La hermenéutica se ofrece como espacio mucho más completo en aquellas zonas de decisión donde el positivismo jurídico no puede decir nada, puesto que no es capaz de explicar asuntos como la restricción que las formulaciones anteriores de la norma continúan ejerciendo sobre el tomador de decisiones que la modifica a través de la nueva interpretación que le da. El litigante, el practicante, el autor de la doctrina y el juez nunca aplican la ley de una manera mecánica: siempre trabajan en la interpretación. Al hacerlo, todos participan en el desarrollo de la ley, que el modelo hermenéutico puede explicar.

\subsection{LA LEGITIMIDAD DE LA LECTURA INTERPRETATIVA DE LOS HECHOS}

Si la interpretación aparece allí donde existe un objeto u hecho interpretable, dentro de los espacios privilegiados en los que aparece la hermenéutica y las grandes disciplinas exegéticas, como es el caso de la literatura, la exégesis bíblica o la historiografía, la ley (y el derecho) ocupa, junto con la medicina, un lugar eminente por su singularidad. 
Esta afirmación supone observar un punto común y una diferencia específica.

El punto en común que comparten estas disciplinas exegéticas es que son conscientes de la necesidad de interpretación debido a la ambigüedad de una declaración o contexto. Pero interpretar nos es molesto, especialmente porque pensamos que da lugar a una inseguridad impropia de una ciencia (literaria, médica, histórica, teológica o jurídica). $\mathrm{Y}$ esta incertidumbre que provoca el carácter voluntario que afecta al hombre no reducido a ser racionalidad pura, surge en la esfera de una racionalidad verificacionista propia de una lectura simplista o reduccionista surgida del horizonte del empirismo.

En este sentido es necesario a modo general reparar en:

1. Que no toda pretensión de racionalidad es científica.

2. Que no toda ciencia es ciencia de la naturaleza física o empírica.

3. Que no todo lo empírico implica una metodología positivista.

4. Que la propia metodología científica del mundo natural contiene una mirada interpretativa para avanzar en el conocimiento nacido de los hechos.

5. Que existen diversas clases de hechos y que el propio hecho no es neutro.

6. Que los diversos hechos suponen diversas aproximaciones racionales con sus propios métodos.

2.2.1. Que no toda pretensión de racionalidad es científica.

La primera impresión que tenemos es que la pretensión de verdad es patrimonio exclusivo de las ciencias naturales, entendidas estas no solo como aquellas que estudian el mundo físico inerte, sino también las que determinan los mecanismos físico-químicos de los seres vivos que pueblan el mundo. En este sentido, tendemos a pensar que el paradigma de la ciencia descansa en las ciencias naturales (física, química...) y en las biomédicas (biología, medicina). Esto se ha llevado incluso al terreno de 
la Academia, en la que los procesos de verificación de calidad universitaria de las áreas de especialización de ciencias y ciencias de la salud (y en menor medida las de ingeniería y arquitectura, en cierta forma híbridas) imponen sus metodologías científicas a las áreas de Artes y Humanidades (aquí de forma obscena) y a las Ciencias Sociales y Jurídicas (aquí subrepticiamente).

La racionalidad humana queda así reducida a la aplicación de un método racional (unívoco) a un tipo exclusivo de hechos, que podemos pasar por la criba de la experimentación. En este sentido, sigue siendo válida la caracterización de Habermas del cientificismo entendido como reducción de la racionalidad, cuando afirma que el cientificismo es "la fe de la ciencia en sí misma, o, dicho de otra manera, el convencimiento de que ya no se puede entender la ciencia como una forma de conocimiento posible, sino que debemos identificar el conocimiento con la ciencia”25. Así, se trataría de un racionalismo miope, superficial y desequilibrado porque no respeta la amplitud posible de la razón, privilegiando uno de sus empleos a todos los demás. No estamos afirmando que toda ciencia sea cientificista, pero sí es verdad que esta visión reduccionista de la racionalidad al cientificismo es compartida por diversas posiciones epistemológicas como es el caso del positivismo, el neopositivismo, la filosofía analítica e incluso algunas versiones del marxismo.

2.2.2. Que no toda ciencia es ciencia de la naturaleza física o empírica.

La visión que normalmente tenemos de la ciencia es tan clara y diáfana que a cualquier espíritu un poco avispado tendría que resultarle, al menos, sospechosa. Y este recelo no es gratuito, como señala John Polkinghorne:

"La imagen que mucha gente tiene en su mente acerca de cómo procede la ciencia es excesivamente simple. Esta engañosa caricatura -

25 Jürgen Habermas, Conocimiento e interés (Madrid: Taurus, 1982), 13. 
prosigue- describe los descubrimientos científicos como el producto de confrontar predicciones teóricas claras e indefectibles con los resultados de experimentos inequívocos y determinantes. La perfecta correspondencia entre ambos vendría entonces a establecer una verdad científica incuestionable. Pero, de hecho, una vez más, la realidad es más compleja e interesante que todo eso" ${ }^{26}$.

De hecho, definir la ciencia no resulta nada sencillo ${ }^{27}$. Dependiendo de lo que entendamos por ciencia, así podremos extender su campo de acción a diversos espacios de la realidad ${ }^{28}$. Una realidad práctica que hemos de tener en cuenta es la reducción que se efectúa al hablar de ciencia respecto del método operado. Hablar de ciencia implica referirse, casi exclusivamente, a la ciencia empírica (siguiendo a Hempel tienen dos objetivos fundamentales: "describir los fenómenos particulares en el mundo de nuestra experiencia y establecer principios generales por medio de los cuales ellos pueden ser explicados y predichos"29) y esta, muchas veces, reducida a ciencia experimental. Cuando el hombre actúa de modo que intenta dar respuesta a la forma en el que las realidades están confeccionadas, la acción humana se denomina ciencia. Para ello se entiende que ha de responder al criterio que siguen las ciencias experimentales. Una visión empírica de la ciencia restringe el campo de estudio a aquello que es, en principio, verificable o falsable. Esto provoca que se excluyan muchas realidades humanas de dicho campo, por no ser verificables. O lo que puede ser más grave y erróneo, que ciertos saberes o modos de hacer restrinjan su campo teórico de explicación a aquellos aspectos que encajan en la ciencia empírica para poder ser consideradas

26 John Polkinghorne, Ciencia y Teología. Una introducción (Santander: Sal Terrae, 200o) 22. Para la caracterización de la ciencia que sigue en el trabajo seguimos nuestro trabajo: Manuel Lázaro, "Ciencia y religión: ¿es posible el diálogo? respuesta desde la filosofía", Naturalea y gracia 52 (2005): 533-544.

27 Cf. Fred N. Kerlinger, Investigación del comportamiento. Técnicas y metodología (México: Interamericana, 1975).

28 Es lo que Thomas S. Kuhn denomina modelos heurísticos que "son objeto de compromisos metafísicos”. Cf. Segundos pensamientos sobre paradigmas (Madrid: Tecnos, 1978), 16.

29 Carl. G. Hempel, Fundamentos de la formación de conceptos en ciencia empírica (Madrid: Alianza, 1988) 9. 
de manera similar. Esto es así porque en la reflexión fácil, la ciencia adquiere un prestigio como verdad objetiva y universal. Pero, quizás, la ciencia no es tan simple como esto, y, quizás, la ciencia la realizan seres humanos, racionales y también volitivos. En este sentido resulta pertinente recordar las palabras de Husserl frente al pensamiento positivista: "Meras ciencias de hechos hacen meros hombres de hechos"30. El fundador de la fenomenología representa un intento de ampliación semántica del término ciencia, que va más allá del campo experimental. Esta introducción significativa, al menos, hay que tenerla en cuenta y no se puede desdeñar, al no ser que caigamos en un positivismo a ultranza y en un escepticismo, que no hace sino justificar la crítica del Husserl a las ciencias experimentales. Por lo tanto, señalemos, por lo menos, que se abre a la consideración (aún controvertida) de ciencia, el hecho de tratar otras disciplinas bajo tal nombre ${ }^{31}$.

Por otra parte, durante mucho tiempo se han establecido criterios de diferenciación entre el campo teórico y la aplicación práctica de constatación teórica, es decir, entre ciencia y tecnología. Para muchos autores en la actualidad resultaría muy problemático realizar esta distinción ante el cambio profundo y la interacción efectuada entre estos dos ámbitos de estudio de la realidad y sus hechos. De modo que "durante el siglo XX la ciencia y la tecnología han experimentado un profundo cambio, generando un híbrido entre ambas, la tecnociencia”32.

30 Edmund Husserl, La crisis de las ciencias europeas y la fenomenología transcendental (Barcelona: Crítica, 1991) 6.

31 "La fenomenología pura, de la cual queremos buscar el camino aquí, caracterizar esa singular posición que ocupa entre las demás ciencias y mostrar que es la ciencia fundamental de la Filosofía, es una ciencia esencialmente nueva alejada del pensar natural, por lo que tiene de peculiar en principio, y, por lo tanto, pugnando por desarrollarse en nuestros días" (Edmund Husserl, Ideen su einer reinen Phänomenologie und phänomenologischen Philosophie Husserliana III, 1950. Texto traducido extraído del artículo José A. Arias, "La fenomenología, un pensar radical (Reflexiones acerca de la distinción husserliana entre "natürliche Geisteshaltung" y "philosophisches Denken")", Anales del seminario de historia de la filosofia 1 (1980): 121-122.

32 Javier Echeverría, “Tecnociencias, capacidades de acción y valores”, Paradoxa 10 (2003) 107. 


\subsubsection{Que no todo lo empírico implica una metodología positivista.}

Olvidar la complejidad de la ciencia provoca que se haya instalado en las mentes un reduccionismo metodológico que afirma que donde no llega la ciencia no se puede llegar. De este modo, la ciencia sería el único lenguaje que pretender ser omnicomprensivo. Pero hoy en día esta visión de la ciencia parece estar, al menos, relativizada. Los modelos de explicación científica son variados y, algunas veces, suscitan en el filósofo de la ciencia no pocas controversias, de modo que la propia expresión "explicación científica” se ha convertido en un tópico33.

Podemos señalar muchas visiones dentro del panorama metodológico34. Por una parte, el neopositivismo lógico afirmaba que la función esencial del lenguaje es descriptiva y apunta a la representación verdadera de lo real. Y esta función sólo lo puede realizar la ciencia, ya que es la única que representa la realidad, pues es capaz de verificar, de comprobar, los enunciados que emite. El mundo -siguiendo a Carnap35tie-ne una estructura lógica y física independiente del hombre, que puede conocer mediante la ciencia. Dicha concepción de la ciencia y del lenguaje del mundo lleva a la crisis de la metafísica que escapa a la representación y al sentido, teniendo en cuenta que éste sólo es posible si puede ser verificado ${ }^{36}$. Para Carnap y el Círculo, el criterio de demarcación se basa en el criterio de sentido de Wittgenstein, en el que una proposición tiene sentido si es una función veritativa de proposiciones

33 Un estudio completo sobre las divergencias en los modelos de explicación científica en Wesley C. Salmon, Four Decades of Scientific Explanation (Minneapolis: University of Minnesota Press, 1989). 34 Una visión clásica de las distintas posiciones de la filosofía de la ciencia en John Losee, Introducción histórica a la filosofía de la ciencia (Madrid: Alianza Universidad, 1987). Sobre las visiones específicamente del siglo XX, cf. Javier Echeverría, Introducción a la Metodología de la Ciencia: la Filosofía de la Ciencia en el siglo XX (Barcelona: Barcanova, 1989); José Antonio López Cerezo, Javier Sanmartín y Marta Isabel González, "El estado de la cuestión. Filosofía actual de la ciencia", Diálogo Filosófico 29 (1994): 164-208.

35 Estructura lógica que la filosofía de la ciencia ha de explicar y describir. Rudolf Carnap, "Logical Foundation of the Unity of Science", en Encyclopedia and Unified Science, vol. 1, $\mathrm{n}^{\mathrm{0}}$ 1, ed. por Otto Neurath (Chicago, Ill: The University of Chicago Press, 1938) 2. Cf. Rudolf Carnap, The Logical Structure of the World. Pseudoproblems in Philosophy (Berkeley, CA: University of California Press, 1969).

36 Cf. Rudolf Carnap, “The Elimination of Metaphysics. Throigh Logical Analysis of Language”, en Logical positivism, ed. por A. J. Ayer (Glencoe, Il, London: The Free Press, Simon and Schuster, 1959), 6o-81. 
"atómicas", es decir, si se pueden reducir de modo lógico a enunciados singulares de observación. El neopositivismo busca el ideal de una Ciencia Unificada por un lenguaje axiomático (lógico-matemático). En esta concepción, la ciencia crece continua y acumulativamente 37.

En la órbita del neopositivismo, el filósofo de la ciencia Karl Popper propone el racionalismo crítico. El filósofo vienés formula como criterio de demarcación científica la falsabilidad. Una contribución que significó en su primera obra (La lógica de la investigación científica ${ }^{3}$ ) una crítica al criterio empirista de significado proponiendo la falsación - no la verificación- como criterio de demarcación o diferenciación de las teorías científicas. La propuesta se interpretó durante mucho tiempo, y bien a su pesar, como una contribución más a los planteamientos epistemológicos de positivismo lógico. Popper empieza poniendo de manifiesto el problema lógico de la inducción, o problema de la validez de las leyes naturales, que surge como resultado de la aparente contradicción existente entre el principio fundamental del empirismo - que lleva a pensar que sin inducción no puede haber conocimiento científico y, según el cual, solo la experiencia puede decidir sobre la verdad o falsedad de un enunciado- $y$ el principio de Hume de invalidez de la inducción, que afirma la imposibilidad de las leyes naturales ${ }^{39}$. Según Popper resulta erróneo pensar que la ciencia empírica procede mediante métodos inductivos. Y, por ende, la ciencia es ilógica si proviene de aserciones singulares, como los informes sobre resultados de observaciones o experimentos, y llega hasta aserciones universales, por ejemplo, hipótesis o teorías, tal y como se suele afirmar que es una inferencia inductiva ${ }^{40}$. A partir de la crítica popperiana

37 El neopositivismo es una posición que lógicamente se retroalimenta desde sus postulados. Cf. Varios, Reexamen del neopositivismo. VI Encuentro de la Sociedad Castellano-Leonesa de Filosofia, 810 de noviembre de 1990 (Salamanca: Sociedad Castellano-Leonesa de Filosofía, 1992).

38 Karl. R. Popper, La lógica de la investigación científica (Madrid: Tecnos, 1985).

39 “...en mi opinión, no existe nada que pueda llamarse inducción. Por tanto, será lógicamente inadmisible la inferencia de teorías a partir de enunciados singulares que estén «verificados por experiencia» (cualquiera que sea lo que esto quiera decir). Así pues, las teorías no son nunca verificables empíricamente". Popper, La lógica de la investigación científica, 39.

40 La historia del "pavo inductivista" mencionada por Bertrand Russell y recordada por el propio Popper puede servir para ilustrar la cuestión: "Este pavo descubrió que en su primera mañana en la granja avícola comía a las 9 de la mañana. Sin embargo, siendo como era un buen inductivista, no sacó 
el criterio empirista de significado, propone la falsación como criterio de demarcación o diferenciación de las teorías científicas. En definitiva, las teorías, siguiendo el modelo lógico del Modus Tollens, funcionan en tanto que no se nieguen, aunque no se puedan verificar, lo que supone abandonar la pretensión de un principio o fundamento absoluto para la ciencia. En el fondo se proponen las teorías sin fundamentos seguros y con base en decisiones subjetivas. Popper acierta a la hora de considerar la ciencia desde el punto de vista lógico-epistemológico, pero ello le lleva a descuidar la influencia del contexto histórico en la creación y desarrollo de la teoría científica. Es decir, en Popper subyace la clásica distinción del positivismo lógico entre contexto de justificación y contexto heurístico o de descubrimiento, inclinándose por el primero en detrimento del segundo.

Las dos teorías anteriores muestran un carácter especulativo del lenguaje y del funcionamiento de las teorías. Las tesis neopositivistas de lo que se conoce desde la calificación de Putman en 1962 como "concepción heredada" 41 empezaron a ser criticadas por diversos autores de ambiente anglosajón como Toulmin, Goodman, el propio Putman... y el mismo Wittgenstein. Pero fue discutida y puesta en solfa, sobre todo, a partir de la obra de Kuhn, La estructura de las revoluciones científicas (1962) ${ }^{42}$ donde muestra, a través de su concepto de paradigma científico, cómo la ciencia no es acumulativa, sino que se mueve por cambios y luchas de paradigmas rivales (ciencia normal y ciencia revolucionaria). La visión de Kuhn lleva a un relativismo epistemológico, sin afirmar el relativismo ontológico. Pero, quizás, lo más importante es que introduce

conclusiones precipitadas. Esperó hasta que recogió una gran cantidad de observaciones del hecho de que comía a las 9 de la mañana e hizo estas observaciones en gran variedad de circunstancias, en miércoles y en jueves, en días fríos y calurosos, en días lluviosos y soleados. Cada día añadía un nuevo enunciado observacional a su lista. Por último, su conciencia inductivista se sintió satisfecha y efectuó una inferencia inductiva para concluir: siempre como a las 9 de la mañana. Pero iay! se demostró de manera indudable que esta conclusión era falsa cuando, la víspera de Navidad, en vez de darle la comida le cortaron el cuello" Citado en Rafael Porlán, Constructivismo y escuela (Madrid: Díada Editora, 1995), 31-32.

41 Hilary W. Putman, "What Theories are Not", Logic, Methodology and Philosophy of Science. Proceeding of the 196o International Congress, ed. por Ernest Nagel, Patrick Suppes, Alfred Tarski (Stanford, CA: Stanford University Press, 1962), 240-251.

42 Thomas S. Khun, The Structure of Scientific Revolutions (Chicago, Ill: University of Chicago Press, 1962). 
elementos externos a la teoría científica como elementos esenciales de la ciencia: una ciencia no se sostiene sólo con base en la propia teoría, sino en la posición de los científicos respectos de teorías rivales. La posición de Kuhn no es la única respuesta radical, podríamos mencionar la propuesta de los programas de investigación científicas del húngaro Imre Lakatos o la más radical posición "anarquista" de Paul Feyerabend 43 .

2.2.4. Que la propia metodología científica del mundo natural contiene una mirada interpretativa para avanzar en el conocimiento nacido de los hechos.

En el último cuarto del siglo XX han tomado consistencia otras consideraciones de explicación de la ciencia como es la sociología de la ciencia. No podemos olvidar que son comunidades científicas las que realizan la ciencia. El "programa fuerte de la ciencia" 44 afirma, profundizando el análisis y extendiendo el objeto de estudio sociológico iniciado por Merton45, que el sujeto de la ciencia es la sociedad; de modo que, si la gente cree que algo es científico, sobre todo si las instituciones y las comunidades científicas aceptan un conocimiento como científico, entonces se ha de considerar esa afirmación como punto de partida de las investigaciones. Lo que se quiere subrayar, interpretando a Kuhn, es que las teorías científicas dependen más del contexto social que de los criterios lógicos o racionales. Lógicamente esto hiere la reflexión epistemológica sobre la ciencia. La visión sociológica de la ciencia ha sido interpretada de diversas maneras. Para algunos (la etnometodología) hay que

\footnotetext{
43 "El siguiente ensayo ha sido escrito desde la convicción de que el anarquismo -que no es, quizá, la filosofía política más atractiva - puede procurar, sin duda, una base excelente a la epistemología y a la filosofía de la ciencia”. Paul Feyerabend, Contra el método (Barcelona: Ariel, 1989), 7; Imre Lakatos, Historia de la ciencia y sus reconstrucciones racionales (Madrid: Tecnos, 1974).

44 El denominado "Programa fuerte de la ciencia" tiene origen en la Universidad de Edimburgo (de ahí que se conozcan también como "Escuela de Edimburgo") y reconoce como inspiradores a Barry Barnes, y David Bloor. Un estudio sobre la crítica a esta visión en Edison Otero, "El «Programa Fuerte» en sociología de la ciencia y sus críticos, Revista austral de ciencias sociales 2 (1998): 89-94.

45 Cf. Robert K. Merton, La sociología de la ciencia (Madrid: Alianza Editorial, 1977).
} 
tener en cuenta los fenómenos microsociales como el trabajo en el laboratorio en el que se investiga y, para otros (el programa empírico del relativismo, años 80), lo que importa es la recepción que de una teoría se tiene en los Congresos, Revistas especializadas.... En este sentido solo la metaciencia se extiende de la actividad filosófico-normativa a la reflexión historiográfica y sociológica de la ciencia ${ }^{46}$.

Un filósofo de la ciencia que podríamos, también, citar es a Ian Hacking. El autor canadiense se inscribe en la línea de P. Berger y T. Luckmann al afirmar que nuestra experiencia de las cosas (las que llamamos "reales") es el resultado de una "construcción social". Según Hacking, en su obra Representing and Intervening ${ }^{47}$, no hay una única metodología de la ciencia, ni inductiva, ni deductiva. Para el autor a la hora de reflexionar sobre el estatus de las ciencias naturales hemos de tener en cuenta el proceso de construcción de las teorías. Así Hacking se pregunta por la propia construcción social de la misma y la difícil distinción entre idea y objeto ${ }^{4}$. Del mismo modo que hay teorías que generan nuevos hechos y experimentos, también hay experimentos e invenciones técnicas que generan nuevos fenómenos y nuevas teorías científicas. El autor intenta rebatir el orden clásico en el que la teoría precede a la experimentación, de modo que el científico cuando observa y experimenta no lo hace para verificar (o falsar) una teoría, sino para producir los fenómenos queridos. Es decir, no se observa y se realizan conclusiones teóricas. La observación y experimentación (lo empírico) están cargadas de teoría y de práctica. No podemos olvidar que entre observador y objeto observado median instrumentos técnicos que reproducen la realidad y no sólo son extensión de los sentidos (por ejemplo, microscopios de rayos X). Es decir, entre la teoría y la experimentación aparece otro componente: la actividad científica.

46 C. Ulises Moulines, Pluralidad y recursión. Estudios epistemológicos (Madrid: Alianza Editorial, 1991), 51 .

47 Ian Hacking, Representing and Intervening. Introductory Topics in the Philosophy of Natural Science (Cambridge: Cambridge University Press, 1983).

48 Ian Hacking, ¿̇La construcción social de qué? (Barcelona: Paidós, 2001). 
La ciencia se abre pues a elementos humanos que van de la estética a la sociología de la práctica científica que se abren a la necesidad de introducir elementos propios de la interpretación. Ian Hacking advierte que el sentimiento de admiración y estético es crucial para la vida científica completando la fórmula "un mundo, una realidad, una verdad"49. Sentimiento que se vive en la practicidad científica. Así, la reflexión actual sobre la ciencia introduce la práctica científica, la comunidad científica, la función de laboratorios e instituciones, la influencia de la tecnología, las polémicas científicas, el impacto de la tecnociencia en el entorno, la influencia de la política científica5 ${ }^{5}$. En fin, la ciencia ha dejado de ser considerada como una forma autónoma de saber y se han estudiado, cada vez más, sus interrelaciones con otras actividades sociales. Todas estas circunstancias desnudan el hecho puro y desarbolan el imaginario del observador neutro, ideas que pretenden desterrar el "engorroso" problema de la interpretación del sujeto sobre los hechos que se dan en un contexto teórico, humano y social y de naturaleza práctica.

Más aún, y en virtud de lo expuesto, podemos ver ejemplos de cómo los supuestos interpretativos que rodena la investigación, algunos tan denostados como los marcos metafísicos o las cuestiones religiosas que rodean los hechos, han resultado claves para el desarrollo teórico de la misma ciencia. Un ejemplo lo tenemos en el profesor de la Universidad de Oxford, John Hedley Brook, quien sugiere como conclusión, a partir de una buena muestra de ejemplos de historia de la ciencia y bajo la inspiración de Ian Hacking, "que la recurrencia del lenguaje religioso en la articulación de la unidad de la naturaleza apoya a aquellos que ponen énfasis las categorías estéticas y existenciales en la construcción de las

49 Ian Hacking, "The Disunities of the Sciences", en The Disunity of Science, ed. por Peter Galison, David J. Stump (Stanford: Stanford University Press, 1996), 109-135.

50 Un análisis de la influencia de la organización del trabajo en los laboratorios tecnológicos en Park Doing, "'Lab Hands' and the 'Scarlet O': Epistemic Politics and (Scientific) Labor", Social Studies of Science 34 (2004): 299-323. Esto no significa que no existe una tensión entre visiones de la metodología más naturalistas y positivistas y otras más sociológicas y la práctica científica. Un estudio sobre esta tensión en Juan Ramón Álvarez, "La filosofía de la ciencia «entre» la epistemología y los estudios (socio)culturales", en Filosofia actual de la ciencia, ed. por Pascual F. Martínez-Freire (Málaga: Publicaciones Universidad de Málaga, 1998), 59-79. 
ciencias naturales" ${ }^{11}$. En contra de la primigenia reacción adversa que la literatura normativa científica ha manifestado frente a la presencia metafórica -en cuanto que introduce una variable de confusión en la función descriptiva de la realidad-, las interpretaciones y concepciones de la ciencia y su práctica de las que venimos hablando han logrado que haya variado sustantivamente la percepción de su uso, muy ligado a la función lingüístico-cognitiva del proceso de racionalización. Además de los mecanismos cognitivo-lingüísticos de la utilización de la metáfora (elemento de simbolización y demandante de la aproximación hermenéutica), cabe preguntarse, también, sobre el mecanismo del hombre en su utilización y de su uso manipulador, en una cierta divulgación de la bonanza científica. De este modo, la metáfora científica en un uso social indiscriminado se esgrime como arma de marketing que se van instalando en el inconsciente colectivo; por ejemplo, la metáfora del ordenador para hablar del cerebro, que obvia, desde la más grosera identificación entre inteligencia y cerebro, el resto de las funciones cerebrales implicadas.

La ciencia, pues, no se reduce a una racionalización externa al hombre en su conjunto, toda vez que ni eso sería posible, pues los lenguajes formales son recreación humana. Y en el ser humano aparecen elementos que escapan a la propia lógica deductiva a partir de hechos neutros. Incluso la defensa de una posición cientificista -dirá Habermas- esconde la presencia de la fe en la ciencia5².

Otro elemento de reflexión que introducía la lectura reduccionista del positivismo científico consiste en la "pretendida" neutralidad axiológica del quehacer científico, que Max Weber llevara al campo de la ciencia

51 John H. Brooke, "Ciencia, religión y unificación de la naturaleza”, Pensamiento 61 (2005): 155. 52 Para el filósofo alemán, el cientificismo o cientifismo es "la fe de la ciencia en sí mismo, o dicho de otra manera, el convencimiento de que ya no se puede entender la ciencia como una forma de conocimiento posible, sino que debemos identificar el conocimiento con la ciencia." Jürgen Habermas, Conocimiento e interés, 13. El término aparece en la literatura filosófica en la obra del premio Nóbel en economía y sociólogo austriaco Friedrich A. von Hayek, The Counter-Revolution of Science: Studies on the Abuse of Reason (Glencoe, Ill.: Free Press, 1952), donde critica el abuso operado al aplicar el método científico en campos como la ciencia social, la economía y la historia económica. 
social y política. Por una parte, cabe preguntarse por el significado de la neutralidad. Pero es muy difícil poder justificar, hoy en día, la neutralidad de la ciencia respecto a los efectos, ni la neutralidad interpretativa de los efectos de la ciencia. Como señala Harding, la información generada por la ciencia se utiliza para desarrollar tecnologías que no son moral o políticamente neutrales. De hecho, la institución científica tiende a ocultar este hecho de diversas formas, especialmente separando los campos científicos en los que la investigación aplicada se ha hecho demasiado evidente53. Esto supone que, si bien se pretende que la objetividad científica no permita una consideración moral de la misma, las coordenadas de análisis actuales en filosofía de la ciencia parecen cada vez más difícil afirmar dicha neutralidad. La tesis defendida por Max Weber sobre la neutralidad de los enunciados científicos (especialmente aplicado al campo de la reflexión de las ciencias sociales) es a su vez axiológica. Efectivamente, la pretensión weberiana, en parte legítima, en contra del abuso del poder intelectual en un mal uso de la libertad de cátedra frente a la normatividad del campo de estudio y de los enunciados propios de una disciplina científica, sin embargo, llevan en sí un componente moral y axiológico (la defensa frente al procedimiento abusivo y coercitivo implícito).

En este sentido, el contexto interpretativo ontológico y metodológico en cuanto inmerso en el mundo humano del intérprete pertrechado de un universo axiológico, en el sentido de axiomas (o convicciones no apoyadas en razones explícitas) y comunidad, se entrelazan en la ciencia, en sus descubrimientos, en su justificación, en su demarcación e interrelación práctica con el mundo. Kurt Gödel, en 1931, afirmó que cualquier formalismo lógico que incluya la aritmética se basa en afirmaciones que son indecidibles o indemostrables, y en algunos casos contradictorias ${ }^{54}$. Estos elementos de convención científica no implican

53 Sandra Harding, Whose science? Whose knowledge? Thinking from women's lives (Ithaca: Cornell University Press, 1991), 3738.

54 Kurt Gödel, "Einige mctamathematische Resultare über Entscheidungsdefinitheit und Widerspruchsfreiheit", en Kurt Gödel, Colleted Works (vol. I, Publications 1929-1936), ed. dirigida por Solomon Feferman, (New York, Oxford: Oxford University Press, 1986), 141-143, publicado en "Über formal unentscheidbare Satze der Principia Mathematica und verwandter Systeme", Monatshefte für 
que la realidad sea en sí convencional, sino que a la hora de hacer ciencia y hablar de la misma, sin reducir la misma a esta visión, no hemos de olvidar que se utilizan representaciones complejas propias del hombre que utiliza con naturalidad situaciones convencionales.

Estas consideraciones no pretenden negar las implicaciones del modelo racional, siempre que desde este modelo (desde una perspectiva no reduccionista) no se anule la influencia de los factores sociales, económicos o políticos..., es decir, el universo hermenéutico, en el conocimiento científico; de modo que no se pueda equilibrar los factores internos y su papel fundamental en la explicación de los contenidos científicos, con el propio papel de la interpretación de estos en el sujeto.

2.2.5. Que existen diversas clases de hechos y que el propio hecho no es neutro.

Hasta ahora hemos visto la dificultad de afirmar una neutralidad en los enunciados de la ciencia, en la búsqueda de los objetivos y en el propio diseño de su procedimiento. Esto supone pensar que, efectivamente, el conocimiento presupone creencias, incluso en sus postulados fundamentales, tal como afirmara el pragmatismo. No podemos, pues, abstraernos a la actividad imprescindible del sujeto, tal como evidenciaran tanto el constructivismo como el perspectivismo. Pero, ante estos límites, al positivismo le queda un atisbo de aproximación cercana a la verdad, sin tener que acudir a un campo externo, ni que atender o pedir auxilio al modelo hermenéutico: la objetividad como característica intrínseca de los objetos.

La objetividad objetual es entendida de forma independiente a cualquier punto de vista presente en la comunidad científica, así "tenemos que ceñirnos a los hechos". Bajo esta perspectiva si una ciencia

Mathematik und Physik 38 (1931): 173-198, que puede verse en Kurt Gödel, Colleted Works (vol. I), 144-195. 
se ciñe a los hechos dados en su forma pura (en bruto) y no sucumbimos a la tentación de extrapolar una teoría científica fuera de su ámbito, entonces tenemos que la ciencia habla "de lo que es", entendida como un reflejo racional de la realidad, y no, por ejemplo, de lo que debe ser (moralidad), del mismo modo que no habla de lo bello, lo justo, etc. De esta forma se podría mantener la neutralidad de los efectos, algo que ya hemos discutido. No obstante, nos queda ver la neutralidad del hecho y su intrínseca objetividad.

Lo primero que cabría preguntarse es qué nos presenta un hecho, si la realidad o lo real. La presencia, al menos teórica, de lo "real" en cuanto una presencia fundante, o como la base ontológica en la que descansa la realidad, es una cuestión que subyace a la problemática enunciada y quizás justifica más si cabe las metodologías no positivistas. Pero nos ceñimos a la comprensión de la "realidad" a la que accedemos mediante la percepción de los hechos. Ahora bien, los hechos siempre se presentan al observador (los busque o se tope con ellos, si bien esto último siempre se da cuando se está buscando).

Ya en el ámbito científico, Henri Poincaré en 1905, realiza, desde lo que se conoce como posición convencionalista, una crítica a la noción de hecho. En ese momento, la ideología dominante en Francia era empirista, o positivista, basada sólo en los hechos. Mach o Duhem atribuyeron a la teoría el único papel de clasificar los fenómenos, no de explicarlos 55 . Frente a ello señala que no hay que confundir los hechos brutos -los hechos tal como son percibidos por los sentidos- con los hechos científicos - los caracterizados esencialmente por su relación con los sentidos, que deciden su verdad o falsedad-. Estos últimos presuponen una síntesis y un sistema de convenciones (lenguaje). Los hechos científicos, de los que se extraen las leyes, se obtienen mediante síntesis sucesivas de hechos más crudos, por ejemplo, los datos elementales de

55 Ernst Mach, Die Mechanik in ihrer Entwicklung (Leipzig: F.A. Brockhaus, 1883). Pierre Duhem, Sozein ta phainomena. Essai sur la notion de théorie physique de Platon à Galilée (Paris: Hermann, 1908). 
los sentidos. Esta síntesis es paradigmáticamente operativa en la construcción de los objetos de percepción ${ }^{5}$. De esta forma la realidad que presentan los hechos brutos, expresados normalmente mediante un lenguaje común, se presentan interpretados, mediante el lenguaje matemático, en tanto que hechos científicos:

"Las leyes invariantes son las relaciones entre los hechos brutos, mientras que las relaciones entre los «hechos científicos» siempre han dependido de ciertas convenciones" 57.

De este modo podemos ver que la experiencia científica es distinta de la experiencia común porque depende de un saber previo. La objetividad que propone Poincaré se aleja de la concepción del carácter intrínseco al objeto. Propone la objetividad, en la introducción a $L a$ Valeur de la science (1905), como una propiedad esencialmente arquitectónica e intersubjetiva, basada en la construcción de un sistema de leyes matemáticas relativas a los fenómenos ${ }^{5}$. En este sentido, los hechos científicos presuponen síntesis (percepciones) y lenguajes (naturales y matemáticos); se obtienen sintetizando más hechos crudos. Poincaré, sin embargo: "no parece creer en la posibilidad de conocer hechos absolutamente crudos. Accedemos a las relaciones entre las cosas a través de las relaciones entre las imágenes que nos vemos obligados a poner en su lugar; estas imágenes son analogías parciales”59. Efectivamente, “el

56 "Les objets extérieurs [...] ce ne sont pas seulement des groupes de sensations, mais des groupes cimentés par un lien constant. C est ce lien, et ce lien seul qui est objet en eux, et ce lien c est un rapport". Traducción mía: "Los objetos externos [...] no son sólo grupos de sensaciones, sino grupos cimentados por un vínculo constante. Es este vínculo, y sólo este vínculo, el objeto dentro de ellos, y este vínculo es una relación". Henri Poincaré, "Sur la valeur objective de la science", Revue de métaphysique et de morale 10 (1902): 290-291. Cf.

57 Traducción mía: "Les lois invariantes ce sont les relations entre les faits bruts, tandis que les relations entre les «faits scientifiques» restaient toujours dépendantes de certaines conventions". Poincaré, "Sur la valeur objective de la science", 208.

58 "La réalité objective [...] ce ne peut être que l'harmonie exprimée par des lois mathématiques. C est donc cette harmonie qui est la seule réalité objective". Traducción mía: "La realidad objetiva [...] sólo puede ser armonía expresada por leyes matemáticas. Por lo tanto, esta armonía es la única realidad objetiva”. Henri Poincaré, La Valeur de la science (Paris: Flammarion, 1905), 23.

59 Traducción mía: “...bien que Poincaré ne semble pas croire à la possibilité de connaître des faits absolument bruts. On accède aux rapports entre les choses par l'intermédiaire de rapports entre images qu'on est forcé de mettre à leur place ; ces images ce sont des analogies partielles". João Principe, "Sources et nature de la philosophie de la physique d'Henri Poincaré", Philosophia Scientiæ 16 (2012): 218, doi: 10.400o/philosophiascientiae.749 
científico debe ordenar; la ciencia está hecha con hechos como una casa con piedras; pero una acumulación de hechos no es más una ciencia del mismo modo que un montón de piedras no es una casa"6o.

La posición de Poincaré es reflejo de la naturaleza compleja de los sistemas teóricos y también el objetivo de la sistematización que se manifiesta en el progreso científico. Efectivamente, es consciente, declara Xavier Verley, que "la invención [...] está enraizada en una memoria colectiva, transmitida a través de la educación y, al mismo tiempo, en una memoria de la especie"61, de ahí que Poincaré recurra a la psicología y a la historia "una de las contribuciones más interesantes de Poincaré"62.

Podríamos objetar que lo que el convencionalismo de Poincaré presenta es una nueva versión del nominalismo, olvidando toda referencia en el lenguaje científico. Pero criticar los hechos brutos no supone caer en la arbitrariedad, sino lo que propone es presentar -más allá de la solución presentada, en este caso el convencionalismo- la precariedad de la noción de "hecho bruto", especialmente visible en ciencias sociales. Como señala Edgar Ascher:

"En la física, por ejemplo, los hechos brutos así constituidos siguen siendo hechos físicos. En esta circunstancia radica la diferencia con las ciencias sociales. En las ciencias sociales, al volver a los hechos brutos, se termina por salir del dominio social, del dominio en el que se trata de comportamientos necesariamente dotados de significados, se llega al dominio físico de los movimientos, de las reacciones químicas, etc. Esto significa que en las ciencias sociales no hay hechos brutos"63.

\footnotetext{
60 Traducción mía: "Le savant doit ordonner ; on fait la science avec des faits comme une maison avec des pierres ; mais une accumulation de faits n'est pas plus une science qu'un tas de pierres n'est une maison". Henri Poincaré, La Science et l'Hypothèse (Paris: Flammarion, 1917), 168.

61 Xavier Verley, Poincaré ou le renouveau de la philosophie naturelle (Paris: Les Belles Lettres, 2009), 19.

62 Verley, Poincaré, 200.

63 Traducción mía: "En physique, par exemple, les faits bruts ainsi constitués sont encore faits physiques. Dans cette circonstance reside la différence avec les sciences sociales. Dans celles-ci, en reculant ainsi vers les faits bruts, on finit par sortir du domaine sociale, du domaine où il s'agit de comportement
} 
Efectivamente, llegados a este punto hemos de recordar que el derecho perteneciendo a las ciencias sociales debe dirimir sobre un hecho teniendo en cuenta tanto el razonamiento como las pruebas que se presentan objetivas. El derecho está obligado a custodiar una cadena de razonamiento que evite las contradicciones y las ambigüedades, evitando las incertidumbres. Pero ello se hará más efectivo teniendo en cuenta la propia naturaleza interpretativa del hecho, pues al no presentarse en bruto, menos en ciencias sociales, es necesario recogerlo teniendo en cuenta la inevitable interpretación. Esto supone que ante la inevitabilidad de dicho proceso es mejor estar prevenidos ante él que obviarlo, por su carácter específico, carácter que genera una cierta incertidumbre e inseguridad. En este sentido, lo que parece más juicioso es tener en cuenta que el hecho jurídico es en sí mismo un hecho interpretado, pues se define como un hecho que como tal se declara en las sentencias, siendo un hecho (en bruto) una acción o una cosa que sucede. Considerar, pues, a su vez, que todo conocimiento está mediatizado por la sociedad y por la comunidad de expertos que los interpreten, como hemos ya puesto en evidencia.

2.2.6. Que los diversos hechos suponen diversas aproximaciones racionales con sus propios métodos.

Más allá de la naturaleza intrínseca y de la fuerza de los hechos, pues no podemos negar su "realidad", y en sintonía con la formulación humana de los mismos, podemos señalar su distinción. Ciertamente, el derecho tiene una evidencia que le es propia basada en la particularidad de su método racional, que es distinto al de las ciencias experimentales o científicas y al de otras ciencias sociales. No estamos bajo ningún concepto negando la racionalidad jurídica que atiende tanto a los aspectos abstractos (usando una lógica deductiva), como a los datos que se presentan (utilizando una lógica inductiva), pues ambas lógicas son

nécessariament doués de significations, on aboutit au domain physique des mouvements, des reactions chimiques, etc. ceci veut dire qu'en sciencies sociales il n'y a pas de fatis bruts". Edgar Ascher, "Problèmes Du Relativisme”. Revue Européenne Des Sciences Sociales 27 (1989): 92. 
compatibles. Lo que señalamos es que existen en los hechos en sí y en su inevitable lectura variables tanto conceptuales (que afectan a la lógica deductiva) como contextuales (que se presentan en la lógica inductiva), dando lugar a la hermenéutica:

"Hay, en el mismo proceso hermenéutico -afirma Giovanni Busino-, dos categorías de reglas, las de interpretación jurídica y las lógicas de inferencia. Las pruebas perfectas son los actos instrumentales, la confesión y el juramento. Los procedimientos de verificación están limitados por su admisibilidad. El juez incluso dictamina sobre la base de pruebas imperfectas siempre que se hayan respetado ciertas normas. Ejerce el poder decidiendo que un hecho particular, o un acto individual específico, tiene las características prescritas para la aplicación de la regla general. En el ejercicio de esta facultad, el tribunal considerará todos los elementos del contexto que no se relacionen, de una manera $\mathrm{u}$ otra, con la actividad del autor del acto en cuestión, con el problema que debe resolver. Por esta razón, el juez decide que un relato es verdadero o más cercano a la verdad o que otro es apenas relevante o admisible. El veredicto impone una decisión, que es vinculante para las partes. Esta decisión es definitiva, a menos que un tribunal superior determine un nuevo hecho. El tribunal dicta su decisión sobre la base de las normas jurídicas y con referencia a los principios generales, sustantivos y procesales" 64 .

64 Traducción mía: "Il y a, dans un même processus herméneutique deux catégories de règles, celles juridiques d'interprétation et les logiques d'inférence. Les preuves parfaites sont les actes instrumentaires, l'aveu et le serment. Les procédures de vérifications sont limitées par leur recevabilité. Le juge statue même sur les fondements de preuves imparfaites pour autant que certaines règles aient été respectées. Il exerce un pouvoir en décidant que tel fait particulier, ou tel acte individuel précis, a les caractéristiques prescrites pour l'application de la règle générale. Pour l'exercice de ce pouvoir le juge scotomise tous les éléments du contexte qui ne se rapportent pas, d'une façon ou d'une autre, à l'activité de l'auteur du fait litigieux, au problème qu'il doit résoudre. Pour cette raison il décide que tel récit est conforme à la vérité ou plus proche d'elle, que tel autre n'est guère pertinent ou recevable. Le verdict impose une décision, contraignante pour les parties. Celle-ci est définitive, sauf fait nouveau estimé tel par une instance supérieure. Il rend sa décision sur la base de normes légales et en se référant à des principes généraux, substantifs et procéduraux". Giovanni Busino, "La preuve dans les sciences sociales", Revue européenne des sciences sociales 41 (2003): 22. 
Por lo que venimos señalando, nos surgen diversos contextos metodológicos en la evaluación de los hechos que ya no puede reducirse a un mero conocimiento, sino a una actividad.

Hablamos, pues, en ciencia de un contexto de educación, innovación, evaluación y aplicación, es decir, de que la propia metodología científica (en sentido fuerte: ciencia experimental) se abre a la elaboración interpretativa en un contexto humano y personal de diversos seres humanos que interactúan de forma sincrónica (elaborando consensos en funciones de verdad y axiológicos) y de forma diacrónica (elaborando una tradición consuetudinaria interpretativa en un saber transmitido: educación).

En este sentido, cabe señalar que, a la división entre hechos brutos y científicos, hemos de ampliar la propia división de los hechos científicos, una vez que hemos establecido que no toda racionalidad se reduce a la ciencia experimental del mundo natural (inorgánico u orgánico). Por lo que los diversos hechos interpretados desde las diversas racionalidades suponen en sí un grado de aplicación de medidas cuantitativas y cualitativas a la hora de interpretarlas. Evidentemente, no es lo mismo analizar la luz que el comportamiento humano, o como se decía en lenguaje escolástico no es lo mismo un acto humano que un acto del hombre.

Ante esta situación parece que estamos abocados a tener que admitir el papel del sujeto que realiza la cuasi inevitable interpretación: el intérprete en sí. Es el intérprete quien es el propio cuestionador de la labor interpretativa. E interpretar no supone no dejarse llevar por la arbitrariedad, lógicamente, sino que es él quien tiene la labor fundamental de evitar las experiencias desafortunadas derivadas de una mala interpretación, es decir, evitar el sentido falso o el sentido contrario. En este sentido ha de procurar poner en claro la equidad, deletrear el significado oculto. La tarea de interpretación es el horizonte del intérprete, su ideal regulador. "El trabajo de interpretación se detendría 
una vez que se aclarara la afirmación o situación: In claris cessat (non fit) interpretatio"65.

Más allá de la propia naturaleza interpretativa de los "hechos" y en consonancia con el polo práctico de dicha interpretación experiencial de los hechos que no aparecen en bruto, el horizonte hermenéutico aparece de forma especial en la interpretación jurídica, donde se da como especificidad propia. Como argumenta Jean-Philippe Pierron:

"al igual que en la medicina -que es en sí el arte de interpretar los signos equívocos del cuerpo enfermo- la ley trabaja para interpretar los signos (las pruebas o las testificales -testimonio-) de la conflictividad inherente en el cuerpo social. De ello se deduce que lo que dramatiza la interpretación médica y jurídica, $\mathrm{y}$, por lo tanto, los distingue, es que ambos están, debido al contexto en el que se desarrollan -la angustia vital del daño sufrido en la enfermedad; la violencia social del mal cometido- ponderadas por un coeficiente -es un eufemismo- de "incidencias" existenciales"66.

El intérprete judicial se enfrenta siempre al peligro de realizar una interpretación errónea. Puede comenter un problema técnico a la hora de interpretar erróneamente el sentido de lo juzgado o del dato sociológico al que se le quiere dar una respuesta legislativa. Pero abocado el derecho a la interpretación, si no se depura la técnica, es más fácil tener errores epistemológicos e incluso éticos a la hora de dejarse llevar en la lectura y la decisión de la presión social, mediática, ideológica... En la trastienda de todo proceso interpretativo judicial (como el del símil anterior de la medicina) se encuentra la sobrecarga del sufrimiento presente en el mismo delito o falta, en la disputa o litigio generado, en la sanción o sentencia final. En el acto legislativo también aparece el hecho

65 Jean-Philippe Pierron, "Une herméneutique en contexte : le droit", Methodos [On line] 13 (2013), consultado el 5 de febrero de 2019, doi: 10.400o/methodos.3040. Ello no supone que una ley de texto claro deba someterse a interpretación cuando parece hallarse en oposición con otras, no para aclarar su texto, pero sí para armonizarlo con el de ellas. Arturo Orgaz, Diccionario de Derecho y Ciencias Sociales (Córdoba: Ed. Assandri, 1961), 192.

66 Pierron, "Une herméneutique en contexte : le droit". 
del sufrimiento: la duda entre dar una respuesta a un comportamiento que genera perturbación, o generar una conducta social mediante la norma. La decisión judicial no responde solo a un problema epistemológico (conocimiento), sino a una cuestión ético-social (reconocimiento), pues el derecho ha de tener presente que no se trata de responder a una cuestión sino de resolver un hecho conflictual.

La interpretación jurídica, a diferencia de la interpretación literaria o histórica -señala Pierron- debe concluir el debate con una decisión que tenga consecuencias prácticas y vitales, de facto el intérprete constituye así el hecho jurídico. Aquí, la interpretación, además de ser una técnica, también se impone como una práctica, que se expresa en la figura simbólica y ritual de este intérprete que es el juez ${ }^{67}$. Lo expuesto ya fue advertido por Pascal:

"Nuestros magistrados han conocido bien este misterio. Sus túnicas rojas, sus erizos, sus gatos de peluche, los palacios en los que juzgan, las flores de lis, todo este augusto aparato, era muy necesario. Y si los médicos no tuvieran sotanas y mulas, y los médicos tuvieran gorras cuadradas y vestidos sueltos de cuatro partes, nunca habrían engañado al mundo, lo que no puede resistir a este reloj tan auténtico. Si tuvieran verdadera justicia y si los médicos tuvieran el verdadero arte de curar, solo tendrían que hacer sombreros cuadrados. La majestuosidad de estas ciencias sería bastante venerable por sí misma. Pero teniendo solo ciencias imaginarias, deben tomar estos instrumentos vanos, que impactan la imaginación con la que tienen que lidiar. Y por eso, atraen el respeto"68.

67 Pierron, "Une herméneutique en contexte : le droit".

68 Traducción mía: "Nos magistrats ont bien connu ce mystère. Leurs robes rouges, leurs hermines dont ils s'emmaillotent en chats fourrés, les palais où ils jugent, les fleurs de lys, tout cet appareil auguste était fort nécessaire. Et si les médecins n'avaient des soutanes et des mules et que les docteurs n'eussent des bonnets carrés et des robes trop amples de quatre parties, jamais ils n'auraient dupé le monde, qui ne peut résister à cette montre si authentique. S’ils avaient la véritable justice et si les médecins avaient le vrai art de guérir, ils n'auraient que faire de bonnets carrés. La majesté de ces sciences serait assez vénérable d'elle-même. Mais n'ayant que des sciences imaginaires il faut qu'ils prennent ces vains instruments, qui frappent l'imagination, à laquelle ils ont affaire. Et par là en effet ils attirent le respect.”. Blaise Pascal, Pensées, ed. por Louis Lafuma (Paris: Seuil, 1978), nº 44. 
Siguiendo el razonamiento de Jean-Philippe Pierron, la afirmación pascaliana que ridiculiza la práctica de los médicos y magistrados como ciencias imaginarias, nace del hecho de que cuando nos enfrentamos a una interpretación, esta necesita pasar por la expresividad gestual y corporal del intérprete para convertirse en un dicho. Así en las áreas donde las consecuencias de la interpretación tienen efectos que afectan de forma significativa la vida de las personas, como es el caso del derecho y la medicina, no pueden tomar a la ligera -ni lo hacen- la interpretación, porque no pueden ignorar que su función como tercer árbitro está habitada por el miedo a la arbitrariedad con consecuencias muy graves para la persona.

El profesor Mauricio Canals, respecto a la medicina, siguiendo el símil propuesto por Peirron, realizaba la siguiente reflexión:

"Un respetado profesor de mis primeros años de estudios de medicina incluía una sencilla pregunta de tres alternativas: "La medicina es: a) un arte; b) una ciencia y c) una ciencia y un arte". La respuesta era "c". Pasado los años, pienso que este profesor quería enseñarnos que la medicina se sustenta en una fuerte base científica, pero que la práctica médica consta de muchos otros aspectos como lenguaje, habilidades de comunicación y relaciones humanas, que no pueden ser enmarcados en el método científico"69.

Siguiendo con esta reflexión, la validez y la exactitud de una interpretación en el ámbito del “derecho” tiene, además de un significado teórico -la luz de la verdad se dilucida en una situación inicialmente equívoca-, un significado práctico -la corrección de la decisión compromete una vida, tiene efectos en la historia vital de las personas. Literalmente conlleva problemas relativas a la vida o a la muerte relacionados con la violencia de la fuerza del derecho. "Si hay un derecho, es decir si existe una oralidad en el derecho pensando en el efecto

69 Mauricio Canals, "Bases científicas del razonamiento clínico: inferencia Bayesiana", Revista médica de Chile 147 (2019): 231. 
retórico que acompaña la escena judicial, es porque el sentido de lo justo no se da inmediatamente de forma intelectualmente evidente, no se agota en la única aceptabilidad racional, sino que se descifra en las expresiones simbólicas que están privadas de una comprensión decorativa de lo simbólico"70. En cualquier caso, para protegerse contra la arbitrariedad, el derecho debe confrontarse con la explicación del estatuto de los signos en los que apoyarse para juzgar y decir el derecho. Y si esto es así no puede extrañarnos que tengamos que abrirnos a la interpretación.

Parece, pues, inevitable abrirnos a pensar sobre la interpretación de los hechos que concurren en la toma de decisiones jurídicas en todo su proceso, desde el legislativo hasta el judicial. La apertura a la interpretación ha venido marcada por su introducción en la toma de decisiones, especialmente en el contexto normativo, sobre la determinación contextual de los hechos y del mismo carácter simbólico del lenguaje explicativo. Siendo esto así, teniendo en cuenta que enjuiciar una situación -para establecer su norma o para resolver un hecho y establecer una racionalidad en los datos- supone siempre un acto de valoración que opera un sujeto humano abierto a la toma de decisiones. En este sentido, el sujeto que valora y decide lo hace con una lógica del entorno que afecta no solo al sentido contextual de un razonamiento lógico (deductivo o inductivo) como hemos señalado.

Las ciencias cognitivas se han convertido en una parte importante del panorama intelectual en los últimos veinte años aproximadamente. Y la neurociencia moderna nos muestra que es el propio razonamiento lógico el que se puede ver afectado.

70 Traducción mía: "S'il y a du droit - voire s'il y a de l'oralité en droit si l'on pense à l'effet rhétorique attaché à la scène judiciaire -, c'est parce que le sens du juste n’y est pas immédiatement donné dans une évidence intellectuelle, qu'il n'est pas épuisé dans la seule acceptabilité rationnelle mais qu'il se déchiffre dans des expressions symboliques qui se déprennent d'une compréhension décorative du symbolique". Pierron, "Une herméneutique en contexte : le droit". 


\section{MÁS ALLÁ DEL DATO PERCIBIDO. RAZONAMIENTO COGNI- TIVO Y HERMENÉUTICA}

La "toma de decisiones" depende de un sujeto dotado de un razonamiento, pero mal haríamos en considerar el razonamiento de forma unívoca, ni tan solo el razonamiento lógico y los tipos de inferencias que existen. Esta evidencia matemática, dentro de un programa de lenguajes formales, no solo afecta al marco teórico, sino que parece cada vez más evidente que tiene un correlato biológico y cerebral. Frente a la opinión más estandarizada de neurobiólogos y psicólogos cognitivos que piensan que no puede haber una teoría matemática universal del cerebro, sino solo modelos restringidos de habilidades cognitivas específicas - puesto que la organización del cerebro humano es el resultado de múltiples evoluciones de los más diversos sistemas seleccionados por su valor de supervivencia, de forma que no podemos asegurar la optimización-, existe un marco distinto de explicación del razonamiento cerebral en las ciencias cognitivas. Este nuevo modelo explicativo se basa en la teoría matemática de la "inferencia bayesiana"71 para modelar una gran variedad de fenómenos psicológicos: percepción, inferencia estadística, toma de decisiones, aprendizaje, procesamiento del lenguaje, etc. A favor de esta explicación teórica se presentan varios factores como la sencillez de sus fundamentos axiomáticos y la profundidad de sus conclusiones justifican que se hable de una verdadera "revolución bayesiana" en las ciencias cognitivas.

El modelo matemático de la inferencia bayesiana alude al razonamiento operado en presencia de incertidumbres y probabilidades. Nadie duda de que tiene que haber un mecanismo lógico-racional a la hora de emprender una decisión ante un contexto de probabilidades. Durante un tiempo este marco lógico estuvo dominado por la lógica

71 La fórmula básica para la probabilidad condicional en circunstancias de dependencia se conoce como Teorema de Bayes. $\mathrm{P}(\mathrm{A} \mid \mathrm{B})=\mathrm{P}(\mathrm{B} \cap \mathrm{A}) / \mathrm{P}(\mathrm{A})$. En términos más generales y menos matemáticos, el Teorema de Bayes es de enorme relevancia puesto que vincula la probabilidad de A dado B con la probabilidad de B dado A. 
borrosa (o difusa72, Pero en el ámbito de la teoría cognitivista y la neurociencia se ha insistido en el modelo bayesiano para responder al tipo de razonamiento probabilístico ${ }^{73}$. Cuando el ser humano, como hemos señalado, por ejemplo, en las ciencias sociales, se tiene que enfrentar a una entrada ambigua de datos, el cerebro reconstruye la interpretación más probable.

En general, lo que propone la regla bayesiana es cómo combinar, de forma óptima, el a priori resultante de nuestra evolución o memoria con los datos recibidos del mundo exterior ${ }^{74}$. Los estudios parecen indicar que muchas decisiones humanas parecen ser el resultado de una aproximación a la regla bayesiana de acumulación de pruebas, combinada con una estimación del valor esperado de las consecuencias de nuestras elecciones.

A nivel neurológico de toma de decisiones (pasar de la percepción a la decisión), según la estrategia que tiene en cuenta el modelo de inferencia bayesiana, se explica mediante un algoritmo que muestra cómo nuestro cerebro se anticipa al mundo exterior (codificación predictiva) y cómo responde a la novedad (propagación de señales de error). Cada estado del mundo (w) se traduce en una distribución de estados sensoriales inferidos (x). El problema de decisión consiste en elegir la acción $(\mathrm{a}=\mathrm{d}(\mathrm{x}))$ en función de los estados sensoriales $\mathrm{x}$. Las

72 Enric Trillas, Claudi Alsina y Josep-Maria Terricabras, Introducción a la lógica borrosa (Madrid: Ariel, 1995).

73 Como escribe: “... aunque con carácter experimental, se utilizan técnicas de lógica difusa o borrosa, que se basan en lo relativo de lo observado como posición diferencial. Este tipo de lógica toma dos valores aleatorios pero contextualizados y referidos entre sí. Lo sistemas basados en lógica difusa imitan la forma de tomar decisiones de los seres humanos, con la ventaja de que son mucho más rápidos. Brindan excelentes resultados y se pueden completar con redes neuronales. Sin embargo, en el momento actual las inferencias bayesianas siguen siendo superiores en la modelación de riesgos y como técnica instriumental para la toma de decisiones". Jaime Rodrigo de Larrucea, La investigación en seguridad. Del Titanic a la ingeniería de la resiliencia (Barcelona: Marge Books, 2018), 78.

74 Seguimos la explicación de Mauricio Canals: "En 1763 Thomas Bayes enunció su famoso teorema: "Dada una partición del espacio muestral A, (ie: diagnósticos) y un evento B (ie: una manifestación: un hecho semiológico, un examen, etc), entonces la probabilidad condicional (o a posteriori) de Ai, dado el evento $B$ (ie: la probabilidad de un diagnóstico dado B) es: $\mathrm{P}(\mathrm{Ai} \backslash \mathrm{B})=\mathrm{P}(\mathrm{B} \backslash \mathrm{Ai}) \mathrm{P}(\mathrm{Ai}) / \Sigma \mathrm{j}(\mathrm{B} \backslash \mathrm{AJ}) \mathrm{P}(\mathrm{Aj})$. Nos indica que para estimar (o actualizar) la probabilidad de un evento es necesario estimar la probabilidad a priori de (P(Aj)) y la probabilidad de que ocurra el evento B dado cada uno de los posibles A. Canals, "Bases científicas del razonamiento clínico", 234. 
acciones tienen consecuencias positivas o negativas que dependen de los estados reales del mundo, según una función de Ganancia (o Costo) $\mathrm{G}(\mathrm{a}, \mathrm{w})$. Una estrategia racional consiste en elegir la acción que maximiza la expectativa de la ganancia G.75 Lo que viene a determinar, aunque de modo especial en el campo de la percepción, la inferencia de los modelos bayesianos en la explicación cerebral es lo que se conoce como "teoría de la codificación predictiva"76. Esta afirma que la función de la organización jerárquica en el córtex es reconciliar las representaciones y predicciones de la entrada sensorial en múltiples niveles. Es decir, "la actividad neuronal está orientada a minimizar el error: la diferencia entre la representación de la entrada en cada nivel y la predicción originada por una representación de nivel superior"77. Así, en esta hipótesis, nuestro cerebro (tipificado como "cerebro bayesiano") infiere, a partir de los aportes sensoriales, un modelo interno del mundo exterior. A su vez, este modelo interno puede ser utilizado para crear anticipaciones sobre las entradas sensoriales. La teoría de la codificación predictiva asume que el cerebro está generando constantemente tales anticipaciones, y genera una señal de sorpresa o error cuando estas predicciones son violadas por entradas sensoriales inesperadas.

Esta teoría-hipótesis supone que nuestro cerebro no es un receptáculo pasivo frente a la entrada y salida de estímulos (y, por lo tanto, de datos sensoriales), sino que es un sistema activo capaz de generar predicciones y verificar su validez. $\mathrm{Y}$ este funcionamiento no genera en el sujeto la sensación de impredecibilidad, sino de cambio de modelación de inferencia estadística. A nivel neurológico implica

75 Laurence T. Maloney, Hang Zhang, "Decision-theoretic models of visual perception and action", Vision Research 50 (2010): 2362-2374.

76 David Mumford, "On the computational architecture of the neocortex. II. The roleofcortico-cortical loops", Biological Cybernetics 66 (1992): 241-251. R. P. Rao, D. H. Ballard, "Predictive Coding in the Visual Cortex: A Functional Interpretation of Some Extra-Classical Receptive Field Effects", Nature neuroscience 2 (1999): 79-87, doi:10.1038/4580

77 Traducción mía: "The neural activities in the whole hierarchy settle to a state where the difference between the prediction and the representation of sensory input is minimal". Naoki Kogo, ChrisTrengove, "Is predictive coding theory articulated enough to be testable?", Frontiers in Computational Neuroscience 9 (2015): article 111, consultado el 6 de febrero de 2019, doi: 10.3389/fncom.2015.00111 
ventajas en los procesos de decisión puesto que el hecho de predecir supone un ahorro de tiempo al disponer de la información con antelación, a veces incluso antes de que llegue a los receptores sensoriales. Utilizar el pasado para predecir el presente también puede ayudar, entre otras ventajas asociadas a la economía epistemológica, a interpretar las entradas sensoriales que no son claras o incluso a reemplazar completamente un estímulo enmascarado, omitido o ausente.

Los investigadores del campo de la neurociencia cognitiva que han estudiado la hipótesis del "cerebro bayesiano" han mostrado su productividad teórico-práctica, de modo que el comportamiento animal y humano sugiere que los adultos y los niños poseen una gran capacidad de inferencia estadística en múltiples niveles (percepción, acción, lenguaje...), es decir que el ser humano aprende a ajustar sus modelos internos en función del entorno en el que se sitúa y la educación que recibe $^{78}$. Lo que es lo mismo, el ser humano individual (¿y colectivamente?) no toma los datos que recibe de forma pasiva, sino que los interpreta ineludiblemente a través de su conocimiento histórico y el entorno cultural.

Lo que nos propone el cerebro bayesiano es la insuficiencia del mero dato para la cognición humana. Esto no supone que nos introduzca en la hermenéutica. De hecho, la hermenéutica contemporánea se niega enérgicamente a concebir las ciencias de la mente a la manera de las ciencias cognitivas, ya sea la neurociencia, la psicología cognitiva o una cierta filosofía de la mente 79 . Pero quizás se puede operar una lectura de las proposiciones de la neurociencia y la investigación cognitiva con las gafas de la hermenéutica ${ }^{80}$. Y no podemos obviar que la hermenéutica filosófica contemporánea se ha esforzado por hacerlo. Más que ninguna

78 Catherine Wacongne, Jean-Pierre Changeux, Stanislas Dehaene, "A Neuronal Model of Predictive Coding Accounting for the Mismatch Negativity", Journal of Neuroscience 32 (14 March 2012): 36653678, doi: https://doi.org/10.1523/JNEUROSCI.5003-11.2012

79 Louis Quéré, "8. Sciences cognitives et herméneutique “, en Paul Ricœur et les sciences humaines, ed. por Christian Delacroix, François Dosse et Patrick Garcia (Paris: La Découverte, 2007), 145.

80 Es el caso de Jean-Michel Salanskis, Herméneutique et cognition (Lille: Presses Universitaires du Septentrion, 2003). 
otra corriente de pensamiento, ha intentado, sin negar nada de sus propios principios, entablar un diálogo con otras tradiciones, pues precisamente lo ajeno, según Hölderlin, es indispensable para toda apropiación de lo propio ${ }^{81}$.

En cierta manera, el pensamiento filosófico que se puede derivar de una mirada a la inferencia bayesiana nos lleva a una reflexión sobre la intencionalidad $^{82}$. La teoría del cerebro bayesiano proporciona un modelo más, un razonamiento de predicción cognitiva, que no anula el carácter estructural de la intencionalidad y la predicción presentes en la hermenéutica, más aún, si concebimos el sentido hermenéutico de una forma más amplia que una corriente filosófica. Entendiendo la hermenéutica como una necesidad de interpretación intrínseca al acto humano de comprender la realidad y tomar decisiones en el actuar, en nuestro caso del derecho, el modelo de inferencia bayesiana proporciona una pista más en la afirmación, hermenéutica, de que las predicciones dependen de la existencia de una estructura que la hace posible (la predicción).

\section{CONCLUSIÓN}

Hemos intentado mostrar a lo largo de esta líneas la necesidad de abandonar una mirada reductiva de la acción racional jurídica, encerrado en un positivismo jurídico de los hechos que muestra a los tomadores de decisiones -sea la decisión de elaborar una norma y crear legislación, sea la de analizar desde la ciencia del derecho la norma y su aplicación, sea en el ejercicio mismo del derecho en su día a día judicialcomo una especie de aparatos lógicos (deductivos e inductivos) capaces de extraer conclusiones infalibles a partir de los datos tal como son, es decir, partiendo de una realidad "en bruto y dada". Es lógica la

81 Friedrich Hölderlin, Correspondencia completa (Madrid: Hiperion, 1990), 545.

82 Un trabajo al respecto sobre la vertiente lingüística de intencionalidad en Claude Romano, "Anscombe et la philosophie herméneutique de l'intention”, Philosophie 80 (2004): 60-87. 
pretensión de eliminar la máxima incertidumbre en la toma de decisiones, pero ello no se consigue eludiendo la necesidad de entender la necesidad intrínseca de la interpretación en el acto de tomar decisiones.

Esta imposibilidad de una neutralidad como fuente de objetividad aparece en los propios datos, es asumido por los estudios epistemológicos referentes a la propia ciencia natural y, por último, hemos visto, es asumida por la ciencia cognitiva. No negamos, en absoluto la existencia de hechos, de datos, de evidencias y de lógicas racionales que los aborden. Pero no podemos obviar el contexto en el que el sujeto percibe e interpreta el hecho: contexto personal, histórico, cultural... Esto no debe ser novedoso, forma parte del acervo jurídico el estudio del contexto: historia, jurisprudencia, teoría, sociología del derecho... A ello se le suma el contexto diario de la toma de decisión tanto en legislación como en la práctica jurídica: presión política, presión mediática, topos contextuales... que afectan la decisión jurídica y alimentan la justificación argumentativa.

La venda de la justicia solo es posible si quitamos el velo de la ignorancia (areté -verdad- significa quitar el velo). Si asumimos el carácter ineludible de la interpretación en todos los elementos de la toma de decisiones que van del dato, al hecho (el dato dado en un momento específico y percibido por el observador), pasando por el sujeto individual y su razonamiento (que es inductivo en cuanto que percibe, predictivo e inferido en cuanto que percibe de un modo determinado, y deductivo a la hora de inferir las conclusiones de lo percibido en contexto y no de forma pura), hasta la toma de decisión que es del sujeto en contexto y del sujeto social en su momento histórico y con su tradición de pensamiento. Ante esta circunstancia no vale con aplicar filtros de objetividad, que siempre son bien recibidos, sino que es necesario dotar de herramientas de interpretación que prevengan desde el mismo acto interpretativo la arbitrariedad como exceso de la subjetividad. 


\section{REFERENCIAS BIBLIOGRÁFICAS}

Álvarez, Juan Ramón. "La filosofía de la ciencia «entre» la epistemología y los estudios (socio)culturales". En Filosofía actual de la ciencia. Editado por Pascual F. Martínez-Freire, 59-79. Málaga: Publicaciones Universidad de Málaga, 1998.

Arias, José A. "La fenomenología, un pensar radical (Reflexiones acerca de la distinción husserliana entre "natürliche Geisteshaltung" y "philosophisches Denken")". Anales del seminario de historia de la filosofía 1 (1980): 121-152.

Ascher, Edgar. "Problèmes Du Relativisme”. Revue Européenne Des Sciences Sociales 27 (1989): 87-122.

Bastit, Michel. "La justice générale selon saint Thomas : une politique de la félicité”. Revue thomiste 114 (2014): 129-142.

Brooke, John H. "Ciencia, religión y unificación de la naturaleza". Pensamiento 61 (2005) 147-156.

Busino, Giovanni. "La preuve dans les sciences sociales" Revue européenne des sciences sociales 41 (2003): 11-61

Canals, Mauricio. "Bases científicas del razonamiento clínico: inferencia Bayesiana”. Revista médica de Chile 147 (2019): 231-237.

Carnap, Rudolf. "The Elimination of Metaphysics. Throigh Logical Analysis of Language”. En Logical positivism, editado por A. J. Ayer, 60-81. Glencoe, Il, London: The Free Press, Simon and Schuster, 1959.

-. The Logical Structure of the World. Pseudoproblems in Philosophy. Berkeley, CA: University of California Press, 1969.

-. "Logical Foundation of the Unity of Science". En Encyclopedia and Unified Science. Vol. 1, $\mathrm{n}^{\mathrm{0}}$ 1, editado por Otto Neurath. Chicago, Ill: The University of Chicago Press, 1938.

Cicerón, Marco Tulio. De Re Publica, 2, 1.2. Cambridge: Harvard University Press, 1961. 
Cumyn, Michelle, Mélanie Samson. "La méthodologie juridique en quête d'identité". Revue interdisciplinaire d'études juridiques 71 (2013): 142. doi https://doi.org/10.3917/riej.071.0001

Doing, Park. “Lab Hands' and the 'Scarlet O': Epistemic Politics and (Scientific) Labor”. Social Studies of Science 34 (2004): 299-323.

Duhem, Pierre. Sozein ta phainomena. Essai sur la notion de théorie physique de Platon à Galilée. Paris: Hermann, 1908.

Echeverría, Javier. Introducción a la Metodología de la Ciencia: la Filosofía de la Ciencia en el siglo XX. Barcelona: Barcanova, 1989.

-. “Tecnociencias, capacidades de acción y valores". Paradoxa 10 (2003): 107-135.

Feyerabend, Paul. Contra el método. Barcelona: Ariel, 1989.

Gadamer, Hans-Georg. Wahrheit und Methode. Grundzüge einer philosophischen Hermeneutik. Tübingen: J.C.B. Mohr, 1975.

Garrido, Manuel J. “Capítulo 1. Los orígenes y la Historia del Derecho”. En Manuel J. Garrido et al. Nociones Jurídicas Básicas. Versión actualizada, 15-33. Madrid: Editorial Universitas, 2012.

Geslin, Albane. "L’importance de l'épistémologie pour la recherche en droit”. En La recherche juridique vue par ses propres acteurs [en línea], dirigido por Bertrand Sergues. Toulouse: Presses de l'Université Toulouse, 2016. Consultado el 15 de diciembre de 2018. http://books.openedition.org/putc/956.

doi: 10.4000/books.putc.956.

Gödel, Kurt. "Über formal unentscheidbare Satze der Principia Mathematica und verwandter Systeme”. Monatshefte für Mathematik und Physik 38 (1931): 173-198.

-. "Einige mctamathematische Resultare über Entscheidungsdefinitheit und Widerspruchsfreiheit”. En Kurt Gödel, Colleted Works (vol. I, Publications 1929-1936), edición dirigida por Solomon Feferman, 141-143. New York, Oxford: Oxford University Press, 1986.

-. "Über formal unentscheidbare Satze der Principia Mathematica und verwandter Systeme". En Kurt Gödel, Colleted Works (vol. I, 
Publications 1929-1936), edición dirigida por Solomon Feferman, 144-195. New York, Oxford: Oxford University Press, 1986.

Goodrich, Peter. "Legal hermeneutics". En Routledge Encyclopedia of Philosophy Online, editado por Edward Craig, Tim Crane. Londres, Nueva York: Routledge 1998. Consultado el 25 de febrero de 2019. doi: 10.4324/9780415249126-To16-1.

Habermas, Jürgen. Conocimiento e interés. Madrid: Taurus, 1982.

Hacking, Ian. Representing and Intervening. Introductory Topics in the Philosophy of Natural Science. Cambridge: Cambridge University Press, 1983.

-. "The Disunities of the Sciences". En The Disunity of Science. Editado por por Peter Galison, David J. Stump, 109-135. Stanford: Stanford University Press, 1996.

-. ¿La construcción social de qué?. Barcelona: Paidós, 2001.

Harding, Sandra. Whose science? Whose knowledge? Thinking from women's lives. Ithaca: Cornell University Press, 1991.

Hart, Herbert L.A. The Concept of Law. Edición de Postscrip por Penelope A. Bulloch y Joseph Raz. Introducción y nototas por Leslie Green, $3^{\text {a }}$ ed. Oxford: Oxford University Press, 2012

Hayek, Friedrich A. von. The Counter-Revolution of Science: Studies on the Abuse of Reason. Glencoe, Ill.: Free Press, $195^{2}$.

Heidegger, Martin. Sein und Zeit. Editado por Friedrich-Wilhelm von Herrmann. Frankfurt am Main: Vittorio Klostermann, 1977. [Heidegger-Gesamtausgabe, Bd. 2, Abt. 1, Veröffentlichte Schriften 1914-1970].

Hempel, Carl. G. Fundamentos de la formación de conceptos en ciencia empírica. Madrid: Alianza, 1988.

Hölderlin, Friedrich. Correspondencia completa. Madrid: Hiperion, 1990.

Husserl, Edmund. La crisis de las ciencias europeas y la fenomenología transcendental. Barcelona: Crítica, 1991. 
Isaac, Jean. Le Peri hermeneias en occident de Boèce à Saint Thomas. Histoire littéraire d'un Traité d'Aristote. Prais: Vrin, 1953.

Kaufmann, Arthur. "Entre el iusnaturalismo y positivismo hacia la hermenéutica jurídica”. Anales de la Cátedra Francisco Suárez 50 (2016): 133-142.

Kelsen, Hans. Reine Rechtslehre. Einleitung in die rechtswissenschaftliche Problematik. Editado por Matthias Jestaedt, sobre la primera edición de 1934. Tübingen: Mohr Siebeck, 2008.

Kerlinger, Fred N. Investigación del comportamiento. Técnicas y metodología. México: Interamericana, 1975.

Kogo, Naoki, ChrisTrengove. "Is predictive coding theory articulated enough to be testable?". Frontiers in Computational Neuroscience 9 (2015): article 111. Consultado el 6 de febrero de 2019. doi: 10.3389/fncom.2015.00111.

Kuhn, Thomas S. The Structure of Scientific Revolutions. Chicago, Ill: University of Chicago Press, 1962.

-. Segundos pensamientos sobre paradigmas. Madrid: Tecnos, 1978.

Lakatos, Imre. Historia de la ciencia y sus reconstrucciones racionales. Madrid: Tecnos, 1974.

Lázaro, Manuel. "Ciencia y religión: ¿es posible el diálogo? respuesta desde la filosofía”, Naturalea y gracia 52 (2005): 527-568.

La Torre, Massimo. "Le modèle hiérarchique et le Concept de droit de Hart”. Revus 21 (2013): 117-139.

Le Moigne, Jean-Louis. Les épistémologies constructivistes. Paris: PUF, 2007.

López Cerezo, José Antonio, Javier Sanmartín, Marta Isabel González. "El estado de la cuestión. Filosofía actual de la ciencia”. Diálogo Filosófico 29 (1994): 164-208.

Losee, John. Introducción histórica a la filosofía de la ciencia. Madrid: Alianza Universidad, 1987. 
Mach, Ernst. Die Mechanik in ihrer Entwicklung. Leipzig: F. A. Brockhaus, 1883.

Maloney, Laurence T., Hang Zhang. "Decision-theoretic models of visual perception and action". Vision Research 50 (2010): 2362-2374.

Merton, Robert K. La sociología de la ciencia. Madrid: Alianza Editorial, 1977.

Moulines, C. Ulises. Pluralidad y recursión. Estudios epistemológicos. Madrid: Alianza Editorial, 1991.

Mumford, David. "On the computational architecture of the neocortex. II. The roleofcortico-cortical loops”. Biological Cybernetics 66 (1992): 241-251.

Muñoz de Baena, José Luis, José Carlos Muinelo (coords.). Filosofía del Derecho. Lecciones de hermenéutica jurídica. Madrid: UNED, Sindéresis, 2019.

Negretto, Gabriel L. "¿Qué es el decisionismo? Reflexiones en torno a la doctrina política de Carl Schmitt”. Revista Mexicana de Ciencias Políticas y Sociales 40 (1995): 49-74.

Orgaz, Arturo. Diccionario de Derecho y Ciencias Sociales. Córdoba: Ed. Assandri, 1961.

Otero, Edison. "El «Programa Fuerte» en sociología de la ciencia y sus críticos. Revista austral de ciencias sociales 2 (1998): 89-94.

Pascal, Blaise. Pensées. Editado por Louis Lafuma. Paris: Seuil, 1978.

Pasquier, Emmanuel. De Genève à Nuremberg. Carl Schmitt, Hans Kelsen et le droit international. Paris: Editions Classiques Garnier, 2012.

Peña, José (coord.). Carl Schmitt y el decisionismo jurídico. Madrid: Fundación Universitaria San Pablo CEU, 2015.

Pierron, Jean-Philippe. "Une herméneutique en contexte : le droit", Methodos [On line] 13 (2013), consultado el 5 de febrero de 2019, doi: 10.4000/methodos.3040. 
Poincaré, Henri "Sur la valeur objective de la science". Revue de métaphysique et de morale 10 (1902): 263-293.

-. La Valeur de la science. Paris: Flammarion, 1905.

-. La Science et l'Hypothèse. Paris: Flammarion, 1917.

Popper, Karl. R. La lógica de la investigación científica. Madrid: Tecnos, 1985.

Porlán, Rafael. Constructivismo y escuela. Madrid: Díada Editora, 1995.

Principe, João. "Sources et nature de la philosophie de la physique d'Henri Poincaré”. Philosophia Scientiæ 16 (2012): 197-222. doi: 10.4000/philosophiascientiae.749

Putman, Hilary W. "What Theories are Not". En Logic, Methodology and Philosophy of Science. Proceeding of the 1960 International Congress, editado por Ernest Nagel, Patrick Suppes, Alfred Tarski, 240-251. Stanford, CA: Stanford University Press, 1962.

Quéré, Louis. "8. Sciences cognitives et herméneutique “. En Paul Ricœur et les sciences humaines, editado por Christian Delacroix, François Dosse et Patrick Garcia, 145-165. Paris: La Découverte, 2007.

Rabault, Hugues. "Le problème de l'interprétation de la loi : la spécificité de l'herméneutique juridique". Le Portique. Revue de philosophie et de sciences humaines 15 (2005). Consultado el 3 de marzo de 2019, URL: http://journals.openedition.org/leportique/587.

Rao, R. P. y D. H. Ballard. "Predictive Coding in the Visual Cortex: A Functional Interpretation of Some Extra-Classical Receptive Field Effects". Nature neuroscience 2 (1999): 79-87. doi:10.1038/4580.

Rodrigo de Larrucea, Jaime. La investigación en seguridad. Del Titanic a la ingeniería de la resiliencia. Barcelona: Marge Books, 2018.

Romano, Claude. “Anscombe et la philosophie herméneutique de l'intention”. Philosophie 80 (2004): 60-87.

Salmon, Wesley C. Four Decades of Scientific Explanation. Minneapolis: University of Minnesota Press, 1989. 
Schmitt, Carl. Politische Theologie Vier Kapitel zur Lehre von der Souveränität. München und Leipzig: Duncker \& Humblot, 1922.

Schleiermacher, Friedrich Daniel Ernst. Sämtliche Werke. Berlín: Reiner, 1835-1864.

-. Hermeneutik und Kritik. Frankfurt a. M.: Suhrkamp, 1977.

Taylor, Charles. La liberté des modernes. Paris: PUF, 1987.

Trillas, Enric, Claudi Alsina y Josep-Maria Terricabras, Introducción a la lógica borrosa. Madrid: Ariel, 1995.

Varios, Reexamen del neopositivismo. VI Encuentro de la Sociedad Castellano-Leonesa de Filosofí, 8-10 de noviembre de 1990. Salamanca: Sociedad Castellano-Leonesa de Filosofía, 1992.

Verley, Xavier. Poincaré ou le renouveau de la philosophie naturelle. Paris: Les Belles Lettres, 2009.

Viala, Alexandre. "Le positivisme juridique : Kelsen et l'héritage kantien". Revue interdisciplinaire d'études juridiques 67 (2011): 95-117. doi: https://doi.org/10.3917/riej.067.0095

Wacongne, Catherine, Jean-Pierre Changeux, Stanislas Dehaene. "A Neuronal Model of Predictive Coding Accounting for the Mismatch Negativity”. Journal of Neuroscience 32 (14 March 2012): 3665-3678. doi: https://doi.org/10.1523/JNEUROSCI.5003-11.2012

Wroblewski, Jerzy. "Les langages juridiques: une typologie". Droit et société 8 (1988): 13-27.

Manuel Lázaro Pulido

Departamento de Filosofía

Universidad Nacional de Educación a Distancia Calle Paseo Senda del Rey, 7 (Edificio de Humanidades) 28040 Madrid (España)

Departamento de Ciencias del Derecho (Chile)

Universidad Bernardo O’Higgins mlazarop@fsof.uned.es https://orcid.org/ 000-0002-0064-5293 